\title{
Numerical and empirical evaluation of a novel building integrated collector storage solar water heater
}

\author{
Celine Garnier ${ }^{1}$, Tariq Muneer ${ }^{1}$ and John Currie ${ }^{1^{*}}$ \\ ${ }^{1}$ School of Engineering and the Built Environment; Edinburgh Napier University, 10 Colinton Road, \\ EH10 5DT, Edinburgh, UK \\ * Corresponding Author, j.currie@napier.ac.uk
}

\begin{abstract}
Integrated collector storage is a long established simple low cost solar water heater configuration combining the solar collector with a storage tank into a single unit. Previous studies have shown the potential of integrated collector storage solar water heaters to significantly reduce domestic energy requirements for water heating, however challenges still remain to integrate them in roof/façades and ensure appropriate domestic hot water demand. In this article, a novel integrated collector storage solar water heaters is being investigated. The configuration and geometry proposed incorporates an embedded heating element to provide a self-contained domestic hot water system and consider roof integration restriction allowing the unit to be embedded within a structural insulated roofing panel system. The proposed system also utilizes an inlet diffuser designed to reduce the disruption to the stratification within the storage during and following draw-off. This article presents a Computational Fluid Dynamic analysis of internal flows and heat transfer regimes within this new collector configuration and compares its performance against previous developed prototypes using empirical testing. The increased aspect ratio of the new design was shown to significantly alter the heating and cooling characteristics of the collector, both gaining and loosing heat at a greater rate than the original prototype. The computational analysis showed that the collector charges effectively with some stratification. Higher draw-off rates however resulted in higher bulk water outlet temperatures, providing better energy delivery efficiency. The inlet diffuser was also shown to improve the thermal efficiency of the unit overall. The empirical testing shows the improvement in performance of this novel integrated collector storage solar water heaters against previous developed prototypes. The study highlights the need to review the effect of draw-off regime upon the performance of such systems in order to identify optimal regime and control strategy.
\end{abstract}

\section{Key Words}

Integrated Collector Storage, Solar Water Heater, Building Integration, Simulation, CFD 


\section{Nomenclature}

Symbols

Twb: water bulk temperature, $\mathrm{K}$

Tp: absorber plate temperature, $\mathrm{K}$

Ta: ambient environment temperature, $\mathrm{K}$

Th: water temperature at local point, $\mathrm{K}$

Tmax: top collector water temperature, $\mathrm{K}$

$\mathrm{H}$ : total length of the collector, $\mathrm{m}$

$\mathrm{h}$ : local length in the collector, $\mathrm{m}$

Q: heat flux applied to the (solar) collector, $\mathrm{W} / \mathrm{m}^{2}$

Tsky: effective sky temperature, $\mathrm{K}$

Tini: water temperature at local point at $\mathrm{t}=0 \mathrm{~s}, \mathrm{~K}$

T: time, s

Abbreviations

ICS-SWH: Integrated Collector Storage Solar Water Heater

MBE: Mean bias error

RMSE: Root mean square error

CFD: Computational Fluid Dynamic

SIPS: Structural insulated panels

U-Value: Heat loss coefficient, $\mathrm{W} / \mathrm{m}^{2} \mathrm{~K}$

\section{Introduction}

Several studies of solar water heating systems have outlined the promising potential of integrated collector storage solar water heaters integrated collector storage solar water heaters (ICS-SWH) in cold climates [1-5]. Additionally the Scottish climate has been shown to be one of the most favourable in Europe for solar water heating, as a 
direct result of having a long heating season [6]. Nationally, domestic water heating is the second most significant energy use in the home, consuming $12 \%$ of the total Scottish heat energy demand [7]. A solar water heater (SWH) design should seek to maximize return not only through high-energy yield and instantaneous operating efficiency, but also on component and installation simplification, with consequential reductions in purchase and installation costs. Within this context ICS-SWHs present several desirable characteristics. In comparison to discrete flat-plate or evacuated tube systems, equipment costs can be significantly lowered by the combination of the two major components in a typical SWH installation. The direct interface between absorber and storage can also significantly reduce the number of ancillary components required, both simplifying installation and further reducing capital expenditure.

Though SWH shows great promise, recent studies have shown that energy savings from installed systems have often been significantly lower than projected. The reasons for underperformance are varied, ranging from poor specification and installation to a lack of operational understanding by end-users $[8,9,97]$. Facing these challenges require a holistic approach to system design, to produce a domestic hot water system that meets the end user's requirements with optimal use of auxiliary heating, while minimizing any requirement for behavioural change. Hestnes [10] suggested that collectors need to be developed in order to meet both technical constraints and also become an architectural element to improve ease of specification and aesthetic appeal to architects. This is supported by the findings of Munari-Probst and Roecker [11] who identified that close synergy between architects and engineers was essential to deliver effective energy efficiency and architectural integration. Buker and Riffat [12] also suggest that the application of solar thermal collectors are still limited partially due to building integration issues. To meet these demands would require a collector specifically developed for integration into the buildings skin, simplifying specification and lowering overall costs.

\subsection{Building Integration}

The UK Government recently stated its commitment to stimulate the supply-side and demand-side of the housing sector to deliver 400,000 new homes by the end of the decade [13]. This increase in construction will have significant implications for the UK's national carbon budget. The magnitude of this impact will be dependent upon how these dwellings are constructed and serviced with energy; calling for efficient and sustainable integrated building systems. Timber construction systems currently account for $65 \%$ of Scotland's new build housing which is projected to grow to $80 \%$ by 2020 . In addition, modular construction is becoming increasingly popular due to its affordability, energy efficiency and sustainability [14-16]. Structural insulated panels (SIPS) is a simple, lightweight and energy efficient prefabricated engineered building material which can be used in modular construction for exterior wall, framing, partition wall, roof, floor and structural framing. [16-18]. SIPs have many 
advantages over traditional methods of construction once of which being their superior insulation values to conventional framing and insulating methods [18-20].

As building fabric becomes more thermally efficient, the need for energy in buildings will derive mainly from hot water services and consumer electricity requirements. A natural next-step will be towards integrating services within the building structure as a one product service. Integrating solar water heaters into roofs depends considerably on the roof type and the design of the solar water heater installed.

\subsection{ICS-SWHs designs}

Previous studies have shown the potential of ICS-SWH [1, 2, 21-23]. While there are no commercial examples of ICS-SWHs in the UK at present, changing regulation and incentives are now making them a potentially attractive proposition particularly when integrated into building fabric. ICS-SWH systems are often affected by their poor overnight performance as their thermal output decreases as the time increases between the availability of solar energy and its use [22, 24]. Many strategies have been proposed to make ICS-SWHs more viable alternatives which include incorporation of: night insulation cover [24, 25], transparent insulation [26-28], baffle plate [29-33], reflectors or concentrators [94-96, 98], phase change materials [34-39, 99-100], and multiple glazing layers [3, 40]. Developing an efficient storage tank design is yet another strategy to enhance the performance of the ICSSWHs. Many storage tank configurations are being researched such as cylindrical [41-44], rectangular [24, 32, 45-52], triangular [30, 53-55], and trapezoidal [36, 56] while others include two parts one exposed and one insulated [32, 33, 57]. While some systems help increase the heat transfer from absorber plate to the water [53, 54], others improve thermal stratification in the water storage tank [56] or both [33, 58, 59] or have better heat retention capability [59-61].

\subsection{Present research}

In the present investigation, a novel rectangular ICS-SWH for use in Scottish homes is being evaluated. These systems are simple, but are characterised by relatively low thermal conversion efficiency. The overall efficiency of ICS-SWHs is strongly related to their capability to capture solar radiation, store the energy collected as well as to their ability to supply hot water at a constant temperature during the discharging phase (draw-off) [44, 62, 99]. Several studies on ICS-SWHs have been performed showing the correlation between good collector performance and high levels of stratification within the storage tank when operated with no or infrequent large draw-offs [5, 33, 63-73]. However when discharging water following that of domestic use, mixing can occurs within the storage tank [44] resulting in decrease in stratification but a potentially higher overall heat transfer from the collector to storage; and consequently better performance [5].

The ICS-SWH system presented in the present paper aims to improve upon existing ICS-SWH designs by integrating an auxiliary water heater in the ICSW-SWH while 
also optimising its geometric and design configuration for installation within a roofing panel with minimal structural impact and optimal thermal performance. The proposed new design aims to optimise the system performance by reducing heat losses while maintaining stratification and the water temperature to a maximum during the whole discharge phase. Based on the literature the proposed ICS-SWH design introduces some notable new features. The configuration and geometry proposed incorporates an embedded heating element to provide a self-contained domestic hot water (DHW) system delivering water at required demand temperatures. Fins are incorporated within the storage volume to improve heat transfer and stratification and increase structural performance. A diffuser manifold has been introduced in the water inlet to minimise disruption to the storage during draw-off and oriented to enable the unit to be embedded within a Structural Insulated Panel (SIPs) roofing system to decrease heat losses. This approach offers a simplification of SWH installation, by removing the requirement for an auxiliary heating system or storage tank in order to provide additional heat when required, as well as ensure safe operation (e.g. pasteurisation for Legionella Pneumophila) and ease of installation in roof structures. The system is further described in section 2.

Testing and performance modelling of ICS-SWHs is essential, as this allows two optimization processes to take place: firstly at the design stage where the system control parameters can be optimized, and secondly during operation the system's response to input can be found, allowing projection of the system's future state. The ability for a control system to base decisions on both predicted usage and ambient conditions, in addition to the current system state, potentially provides significant opportunities for further system optimization. When studying stratification within ICSSWHs it is appropriate to consider two main operational cases: static operation (nodraw-off, quasi steady-state) and dynamic operation (during or following draw-off, transient operation). Steady-state modelling, as typically applied to flat plate collectors, can provide insights into the diurnal performance of the system. However, to produce a model representative of actual system performance needs to account for the continuously transient interaction between the absorber and storage [5].

To test the performance of the new ICS-SWH design both computational and experimental analyses were carried out. The numerical simulations allowed analysing the thermal field inside the collector and showed initial findings of its thermal characteristics for water heating during insolation (charging), draw-off and cooling, allowing detection of possible improvements to the present configuration. While many studies focus on the benefits of stratification, very little consider the discharging phase. Such a study is essential for further optimisation of the ICS-SWH for use and is presented in this paper. In particular, the Computational Fluid Dynamic (CFD) analysis gave an insight of the internal flow and heat transfer regimes, allowing to understand the mechanism inside the collector and thermal characteristics of the newly proposed design; and to help specify a control system to take a more refined approach to meeting end user demand while minimizing auxiliary 
energy requirements while maximizing total yield from an array of units. Even if similar studies have been conducted on ICS-SWHs [92-93, 99-100], none of them can be readily referred to ICS applications with such configurations. On the other hand, experiments gave an indication of the new collector's thermal characteristics / performance against a formerly developed prototype using empirical testing assessing the main bulk water temperature achieved, stratification and energy storage and loss rates during heating and cooling cycles under steady state operations.

\section{System designs}

The new ICS-SWH is an evolution of the design that has been researched at Edinburgh Napier University and previously reported [5]. In an attempt to address the issues highlighted above with current ICS-SWHs, numerous design modifications have been proposed to the original ICS-SWH configuration. An exploded illustration of the new design is presented in Figure $1 \mathrm{~b}$. The newly proposed design aims to improve upon existing ICS-SWH designs by optimising its geometry for integration within a SIP roof system with minimal structural impact and including an auxiliary water heater within the design in order to deliver water pasteurisation against legionella, required hot water delivery temperatures to users, and a degree of freeze tolerance for installation in northern climates. The features and rationale of this design are discussed further in this section.

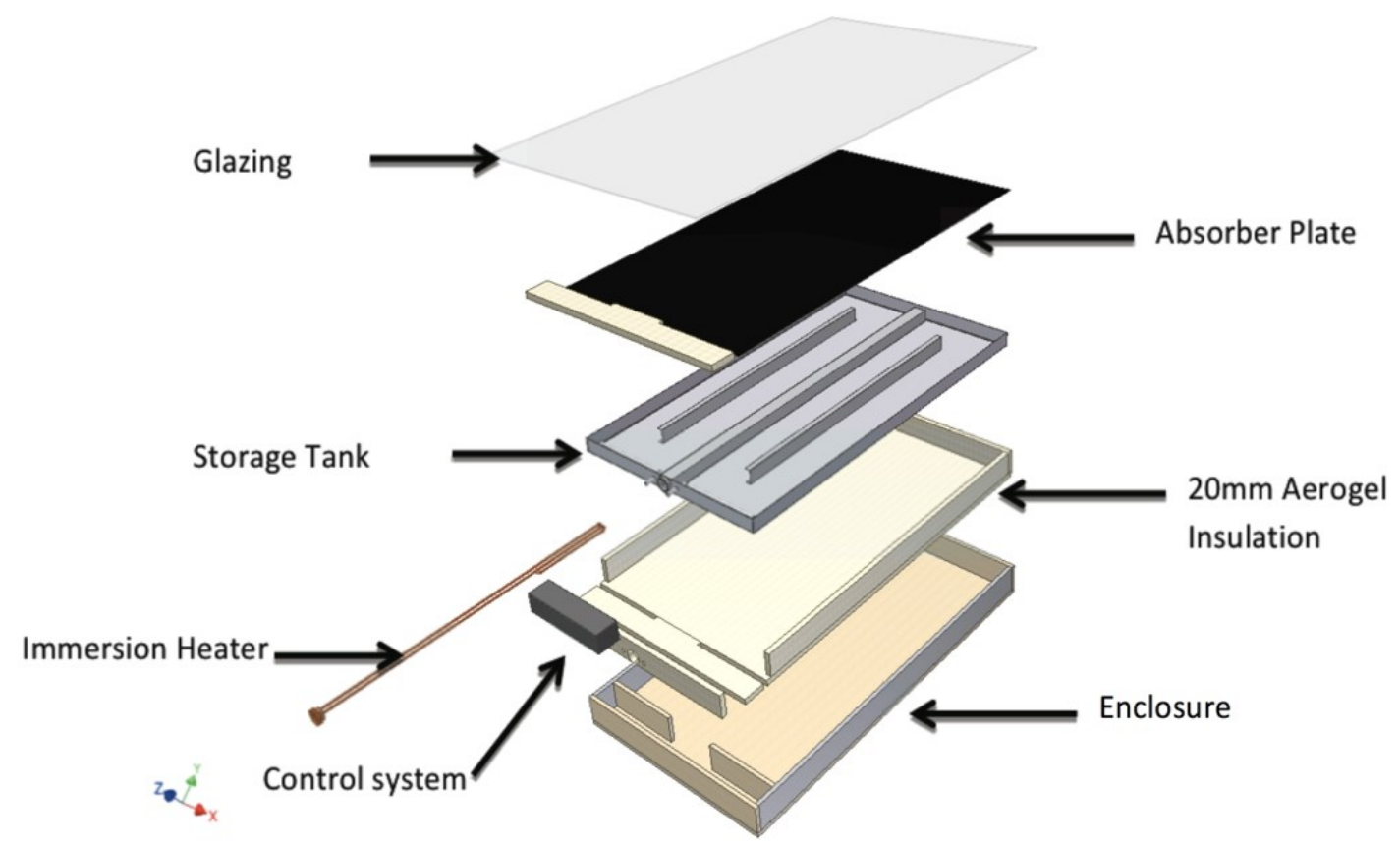

Figure 1: Exploded view of new ICS-SWH design

Based on previous studies, the improved ICS-SWH design was manufactured using $1.5 \mathrm{~mm}$ thick aluminium sheets and incorporated fins to improve the thermal efficiency and structural stability of the 50mm deep storage tank [4-5].. From 
discussions with structural engineers of roof systems a maximal width of $800 \mathrm{~mm}$ for the ICS-SWH assembly was found to be acceptable in order to maintain appropriate factors of safety for the roofing panels' structure. The dimensions of the new ICSSWH $\left(1400^{\star} 700 \mathrm{~mm}\right)$ were thus derived from this width constraint in order to maintain a storage volume of $50 \mathrm{O}$.. Integrating an auxiliary heating element, as shown in Figure $1 \mathrm{~b}$, directly into the storage volume enabled a truly integrated, self-contained, hot water heating system to be delivered which could boost the delivery temperature of the system for user needs and provide a degree of frost protection during winter months. Considering the above and the change in aspect ratio of the ICS-SWH two fins mounted on each side of the draw-off tube are proposed, with water being able to circulate from one side of the tube to the other via channels formed at either end. Draw off is performed via an internal manifold, which allows all penetrations through the SIP to be localised, reducing the required number of seals through the building's thermal envelope. As stratification within ICS-SWH has been shown to be advantageous, two inlet diffusers have been installed to reduce disturbance during draw-off [74, 77-81]. The water tank was then placed in a plywood box insulated with a $20 \mathrm{~mm}$ thick layer of aerogel insulation on all sides and bottom to consider the limited availability of physical space in the box. Based on previous studies, a gap of $35 \mathrm{~mm}$ between the absorber plate and glazing was used to reduce heat losses by restricting air movement. When integrating the ICS-SWH into the roofs structure, it is possible to use standard glazing fittings for a roof window. This simplifies construction of the roof, and allows the roofing contractor to use standard flashings to ensure weather tightness. Tempered glass is used for the collector glazing providing a good balance of durability with cost. The proposed concept design configurations embedding the prototype ICS-SWH into a closed panel roof is shown in Figure 2.

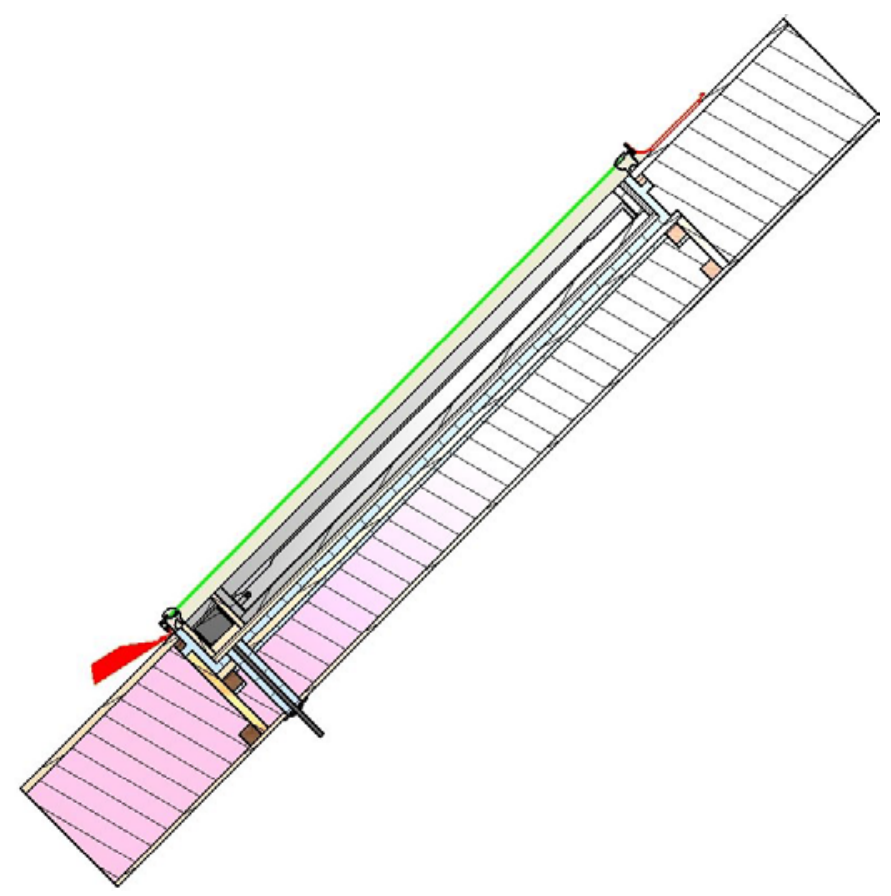

Figure 2: ICS-SWH roof assembly details - panel embedded into SIPS roof 


\section{Methodology}

\subsection{Numerical simulation: Computational Fluid Dynamic (CFD)}

The integration of the collector into the storage prevents using the quasi steady state methodology typically employed for calculating the efficiency of a discrete SWH. Instead a holistic approach is required to analysis; which can be partially fulfilled through the use of CFD-Fluent. CFD enables the analysis and visualisation of fluid and heat flow in a structure that is not physically possible, and allows the calculation of effects within geometry too complex to manually decompose for traditional numerical study. While the successive approximation inherent in CFD means that it cannot replace empirical testing, it can provide a valuable complement to guide the development of an experimental testing regime and can identify the significant operational characteristics and design parameters.

A CFD analysis of a system is performed via a series of steps. The geometry of the features to be studied is first defined before being decomposed into a computational mesh with discrete domains for each material and point of interest. The physical properties for these domains are specified and the interaction between their boundaries defined. Following this, the strategy used to derive a solution and appropriate variable monitors are defined. These allow the solution state to be monitored during computation for convergence checking, before running the simulation. The quality of results derived from a CFD analysis is dependent upon the quality and appropriateness of the mesh created to ensure that phenomena are captured with sufficient detail [84]. Critically the elements need to be of high orthogonal quality and near boundaries sized to fit within the flow boundary layer. The geometry of the ICS-SWH is complex to decompose as a result of the disparity in scale between the thin sections of the enclosure and the relatively large volumes of fluid contained within them. Previous studies CFD studies of the ICS-SWH have utilised the Boussinesq model to account for buoyancy forces within the flow [52, 85]. However the larger temperature differentials within the fluid domains expected as a result of the integrated heater precluded this approach. Consequently, the analysis was performed transiently with the fluids' properties defined as polynomial functions of temperature (Table A1 \& A2) with property data being provided in Table A3 in Appendix A.

Previous studies of the ICS-SWH have assumed isothermal operation at the exterior of the ICS-SWH domain $[52,85]$. In contrast this study allowed heat transfer to occur through the casing to the exterior roof structure. Other boundaries were defined as coupled, with the exception of the boundary between the glazing and the exterior, which transfers heat both via radiation and convection to the surroundings. Though more computationally expensive than the Surface to Surface model typically employed for solar collector simulation when modelling radiation the Discrete Ordinates model was used to accommodate the symmetry condition created at the longitudinal mid-plane of the ICS-SWH [87]. 
Ansys ${ }^{\circledR}$ Fluent ${ }^{\mathrm{TM}}$ uses the finite volume method (FVM) to solve the governing equations. As the flow within the ICS-SWH is incompressible, the energy conservation equations can be calculated separately and the segregated implicit solver was used. To accelerate convergence towards an acceptable solution, the momentum and energy equations were solved initially using the first order upwind differencing scheme before using a second order scheme for subsequent calculation. To take account of the density changes of the fluid within the ICS-SWH a body-force-weighted discretization scheme for pressure was used. The PISO (pressure-implicit with splitting of operators) algorithm was used as recommended by Ansys ${ }^{\circledR}$ with the standard k- $\varepsilon$ turbulence model [87].

In the present work CFD cases were developed to assess operation during charging, draw-off (with and without auxiliary heat); recovery from draw-off; cooling and auxiliary heating of the storage.

\subsubsection{Charging}

The primary function of a SWH is to transfer the incident radiation upon it into useful heat. Therefore, a relationship needs to be developed between the heat flux upon the collector and the amount of energy stored. The ICS-SWH absorbs radiation at the surface of the absorber plate, which is conducted through the absorber plate and casing, and then transferred via convection to both the water cavity and the air gap. Heat is lost from the storage via the air gap and the glazing to the exterior, and through the casing to the building fabric. The operation of the ICS-SWH is continuously transient in nature as the convective flows within the cavities influence each other.

Previous CFD studies and empirical testing $[52,85]$ of ICS-SWH have been performed with good correlation between each other by applying heat flux directly to the collector surface. The same assumption has been made in this study. Radiation is a very small component of the heat transfer within the ICS-SWH, and the computational expense of radiation transfer models can be high. To provide a replicable set of parameters for empirical testing the operating conditions were defined as $20.5^{\circ} \mathrm{C}$ ambient and the convective heat loss coefficient from the glazing to the ambient as $12 \mathrm{~W} / \mathrm{m}^{2}$. $\mathrm{K}$. The above temperature corresponded closely to the ambient temperature of the laboratory where empirical testing was carried out. The numerical value of the convective heat loss coefficient was obtained from CFD simulation. Previous research in ICS-SWHs suggest that the degree of stratification and temperature fields after long exposure are more dependent on the absorbed energy than the heat flux dynamics pattern [91]. As a result, a constant heat source generating 100, 250 and $400 \mathrm{~W} / \mathrm{m}^{2}$ across the upper surface of the absorber plate was applied in the model. This application of steady conditions allows the flow development and resultant behaviour of the ICS-SWH to be quantified. The simulation was performed up to ten hours of operation to allow the flow regime to develop further toward steady state operation. 


\subsubsection{Draw-off}

The draw-off characteristics of the ICS-SWH were assessed by testing two different draw-off rates. These were selected to represent both the maximum possible rate while remaining under $1.5 \mathrm{bar}$ operating pressure and the average draw-off rate observed for typical household activities (dishwashing, showering) of $6 \mathrm{l} / \mathrm{min}$ [88]. As the ICS-SWH storage has been sized to match the daily requirement for a single occupant the number of units installed to meet demand is projected to correspond with the number of occupants within the residence. The average household size in Scotland being 2.17 occupants [89], three ICS-SWH units would be installed in parallel to meet this demand. An arrangement in which the collector modules were connected in parallel was found to provide higher heat collection and better stratification stability within ICS-SWHs [93]. When installed in this configuration to meet the total draw-off required for typical activities, each unit would deliver water at the rate of $2 \mathrm{l} / \mathrm{min}$. To minimise cost of manufacture and remain within electrical supply constraints a standard immersion heater with a rated power of $3 \mathrm{~kW}$ at 230Vac was selected. At each rate of draw-off, auxiliary heat was added via the immersion heart at $1.5 \mathrm{~kW}$ and $3 \mathrm{~kW}$. Under Scottish weather it was assessed that the incident irradiation transmitted through the glazing under a clear sky would be around $400 \mathrm{~W} / \mathrm{m}^{2}$. Hence, using the results obtained from the $400 \mathrm{~W} / \mathrm{m}^{2}$ charging simulation at 8 hours the draw-off tests were run for 200 seconds to allow the hydrodynamic-flow through the ICS-SWH to develop sufficiently for analysis. These cases are detailed in Table 1. The draw-off temperature, operating efficiency of the heater, and the operating characteristics of the inlet manifold were monitored and evaluated.

Table 1: Draw-off test cases

\begin{tabular}{|llll|}
\hline Case & $\begin{array}{l}\text { Nominal rate } \\
\text { (l/min) }\end{array}$ & $\begin{array}{l}\text { Duration } \\
\text { (s) }\end{array}$ & $\begin{array}{l}\text { Aux heat input } \\
\text { (kW) }\end{array}$ \\
\hline 1a & 2 & 200 & 0.0 \\
1b & 2 & 200 & 1.5 \\
1c & 2 & 200 & 3.0 \\
2a & Max* & 200 & 0 \\
2b & Max & 200 & 1.5 \\
2c & Max & 200 & 3.0 \\
\hline
\end{tabular}

${ }^{*}$ Maximum flow rate $=6 \mathrm{I} / \mathrm{minute}$

\subsubsection{Recharging}

To gain an insight into the operation of the ICS-SWH when recharging, following a draw-off event, the results from the two draw-off tests with no additional heat flux were used as the initial point for an hour long charging period at $400 \mathrm{~W} / \mathrm{m}^{2}$. The results from the 8 hours exposure to $400 \mathrm{~W} / \mathrm{m}^{2}$ were extended for 1 hour, allowing comparison to be made both between the relative rates of recovery from each case and the continued charging of an undisrupted ICS-SWH. 


\subsubsection{Cooling}

Direct cooling of the storage occurs when the heat losses exceeds the heat input. Quantifying the ability of the ICS-SWH to retain heat during periods of low or no insolation is critical to successful design. The radiative heat loss to the sky from the ICS-SWH becomes significant during cooling and consequentially needs to be taken into account using Equation 1 below.

$$
Q_{r n l}=\sigma\left(T_{p}^{4}-T_{s k y}^{4}\right) \quad \text { Equation } 1
$$

As with the charging test regime, a set of replicable parameters was used to enable comparison with empirical testing. The ambient temperature was set at $0.0^{\circ} \mathrm{C}$ to correspond to winter ambient conditions in Scotland. To enable calculation of the radiative losses from the collector, the effective sky temperature is required, which has been derived from a modified Swinbank model [90] assuming a clear night sky with $10 \%$ relative humidity providing an effective sky temperature, $T_{s k y}$, of $-14.56^{\circ} \mathrm{C}$. Starting from the end state of the charging test for both 250 and $400 \mathrm{~W} / \mathrm{m}^{2}$ applied flux the simulation was performed for a period of 4 hours.

\subsubsection{Auxiliary storage heating}

To determine the operating characteristics of the embedded auxiliary heater, the final results and parameters of the cooling test from the $250 \mathrm{~W} / \mathrm{m}^{2}$ charged state were used, and the auxiliary heater power output defined as $500 \mathrm{~W}$ and $1 \mathrm{~kW}$. The tests were performed to cover a simulation period of 30 minutes.

\subsection{Empirical testing}

While a numerical analysis allows to evaluate the new collector's thermal behaviour, empirical tests are required to compare its overall performance against previous prototype. The methodology used in this research is similar to that of previous studies of rectangular ICS-SWH systems [3, 49-51, 67, 82] to allow comparison of previous prototypes performance against the newly proposed design. The experimental investigation was performed to simulate Edinburgh's local winter weather conditions $(56 \mathrm{~N}, 3.4 \mathrm{~W})$.

A silicone rubber heating pad connected to a timer controlled variable transformer was used to regulate the power input on the top surface of the water tank. The heating pad simulated constant and uniform heat flux over the collector. In order to measure the temperature stratification within the ICS-SHW an array of 18 calibrated K-type thermocouples were installed throughout the storage cavity and connected to a data-acquisition system. Other thermocouples were used to record the absorber plate, the glass cover, the ambient, and the inlet and outlet water temperatures. Accuracies of the experimental components suggested a system's accuracy of $\pm 0.6{ }^{\circ} \mathrm{C}$. The experimental test rig and positions of thermocouples in the water tank along length are illustrated in Figure 3 . 
To investigate the performance of the collectors, tests were carried out for heat fluxes from 100 to $400 \mathrm{~W} / \mathrm{m}^{2}$ reproducing typical Scottish winter conditions. The collector was positioned at an angle of $35^{\circ}$ from horizontal [83]. Temperatures were recorded at $10 \mathrm{~min}$ intervals over 10 hours during the application of heat and then for 13 hours during cooling.

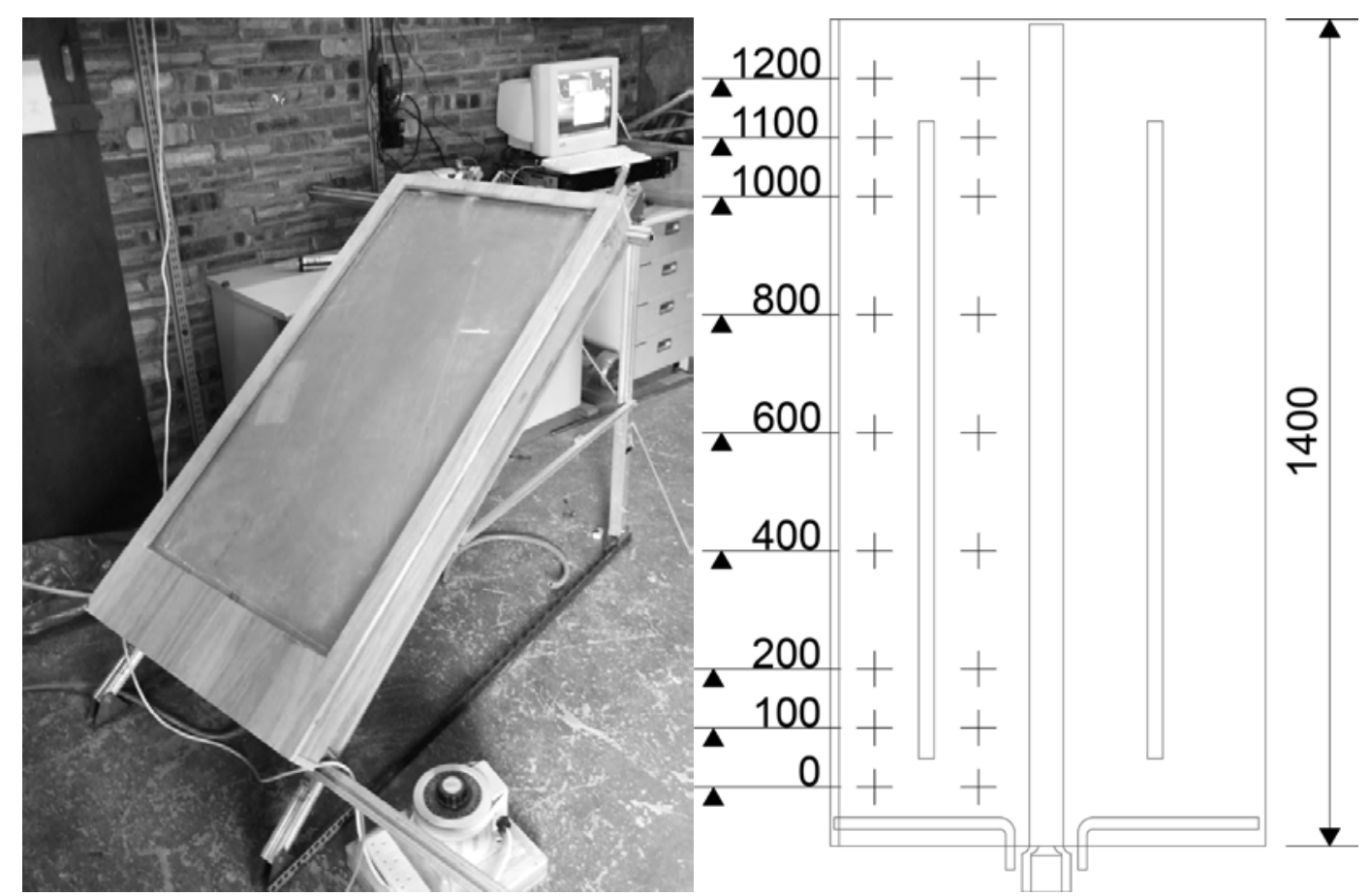

Figure 3: Experimental test rig and thermocouple positions within storage

\section{Results and Analysis}

\subsection{CFD numerical simulation}

\subsubsection{Inlet optimisation}

The effect of inlet design on the performance of the ICS-SWH was first investigated in order to optimise flow field development and to increase collector thermal efficiency. Figure 4 shows the velocity profile within the ICS-SWH for an average draw off rate of $3.51 /$ minute. 

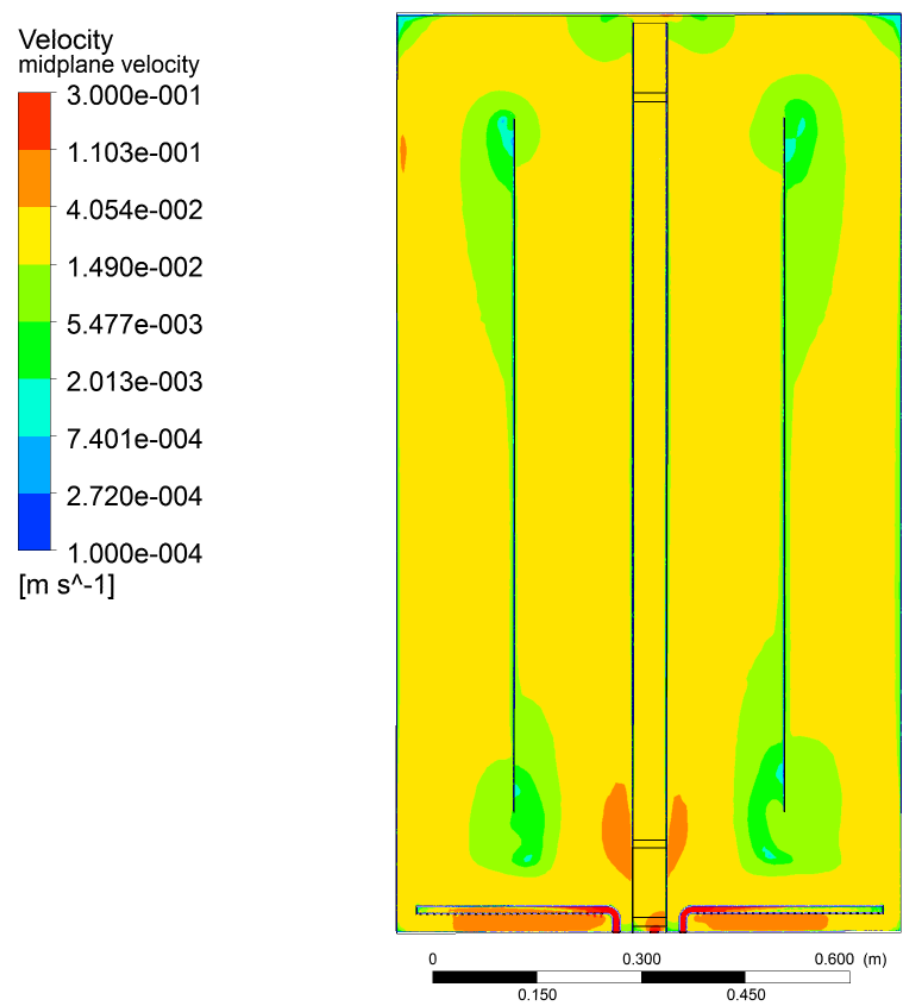

Figure 4: ICS-SWH 3.5I/min draw off steady state mid-plane CFD results

Figure 5 shows the improvement in providing a more even flow through the ICSSWH during maximum draw-off. This was achieved by resizing the diameter of outlet holes. These results are comparable to the results reported in earlier research [74, 77-81].

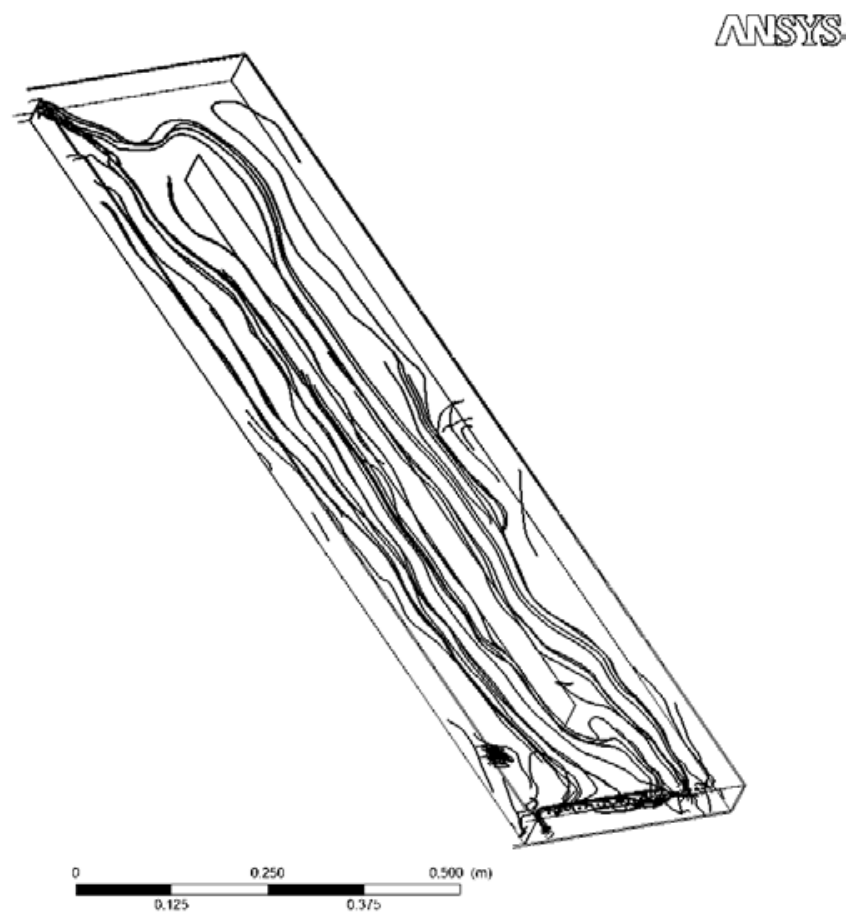

Figure 5: ICS-SWH 3.5I/min draw off: CFD generated fluid streak lines 
Using the above model, both steady state operation and transient operation to provide insights into the internal characteristics of the ICS-SWH were then undertaken to allow further design optimisation to be identified and are presented below.

\subsubsection{Charging Cycle}

The bulk temperature of the water within the ICS-SWH has been plotted against time for differing rates of heat flux as shown in Figure 6 . This shows that for each heat flux there is a corresponding rate of temperature increase, which decreases with time leading toward a stagnation temperature for each level as the ICS-SWH approaches steady state operation.

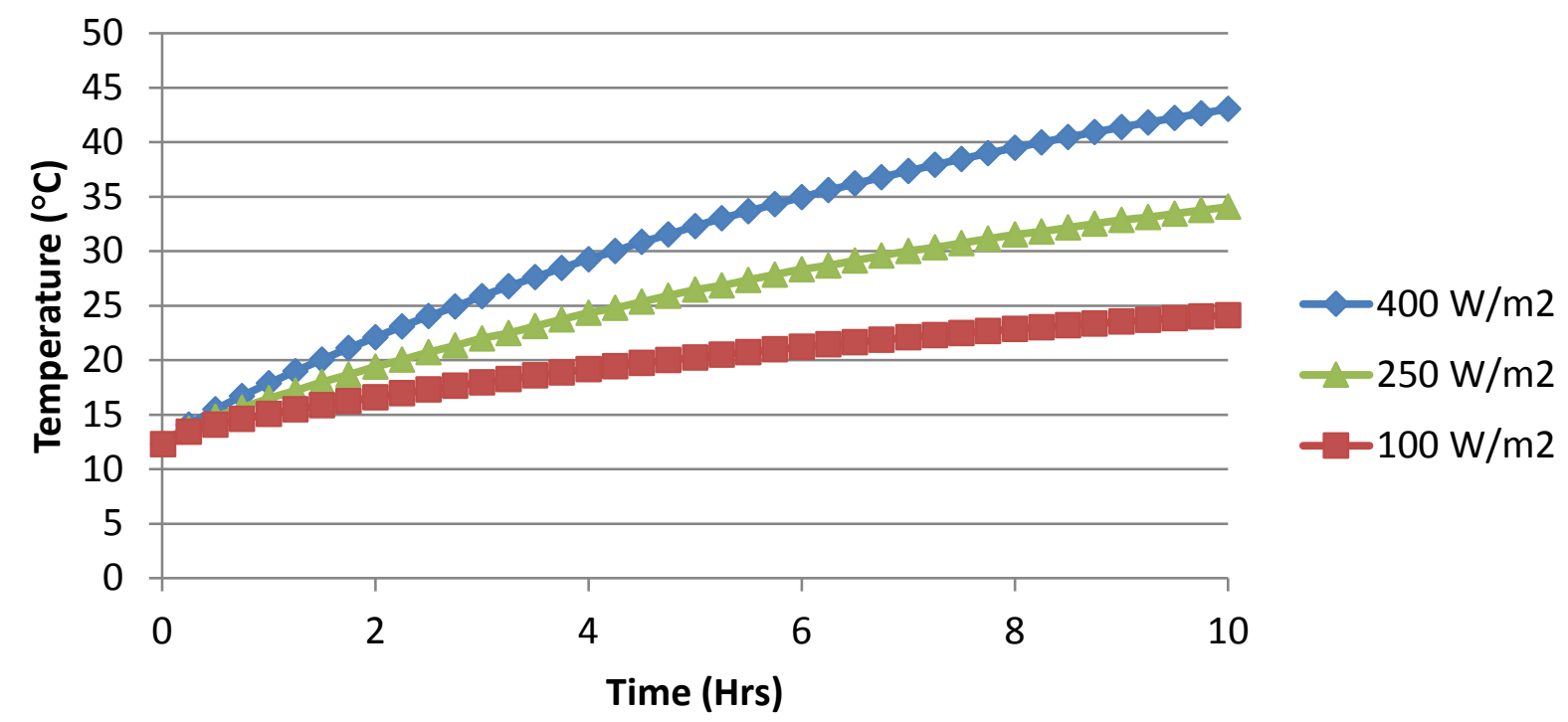

Figure 6: Average bulk water temperature with time at differing heat flux rates

Figure 7 shows the relationship between the absorber plate temperature and the fraction of imposed heat flux entering the water cavity. This shows good correlation with the expected linear relationship between these parameters. Additionally, by extending this linear relationship at each imposed heat flux it is possible to predict the plate temperature at which stagnation will occur (i.e. when the fraction of heat entering the cavity reaches 0 ). 


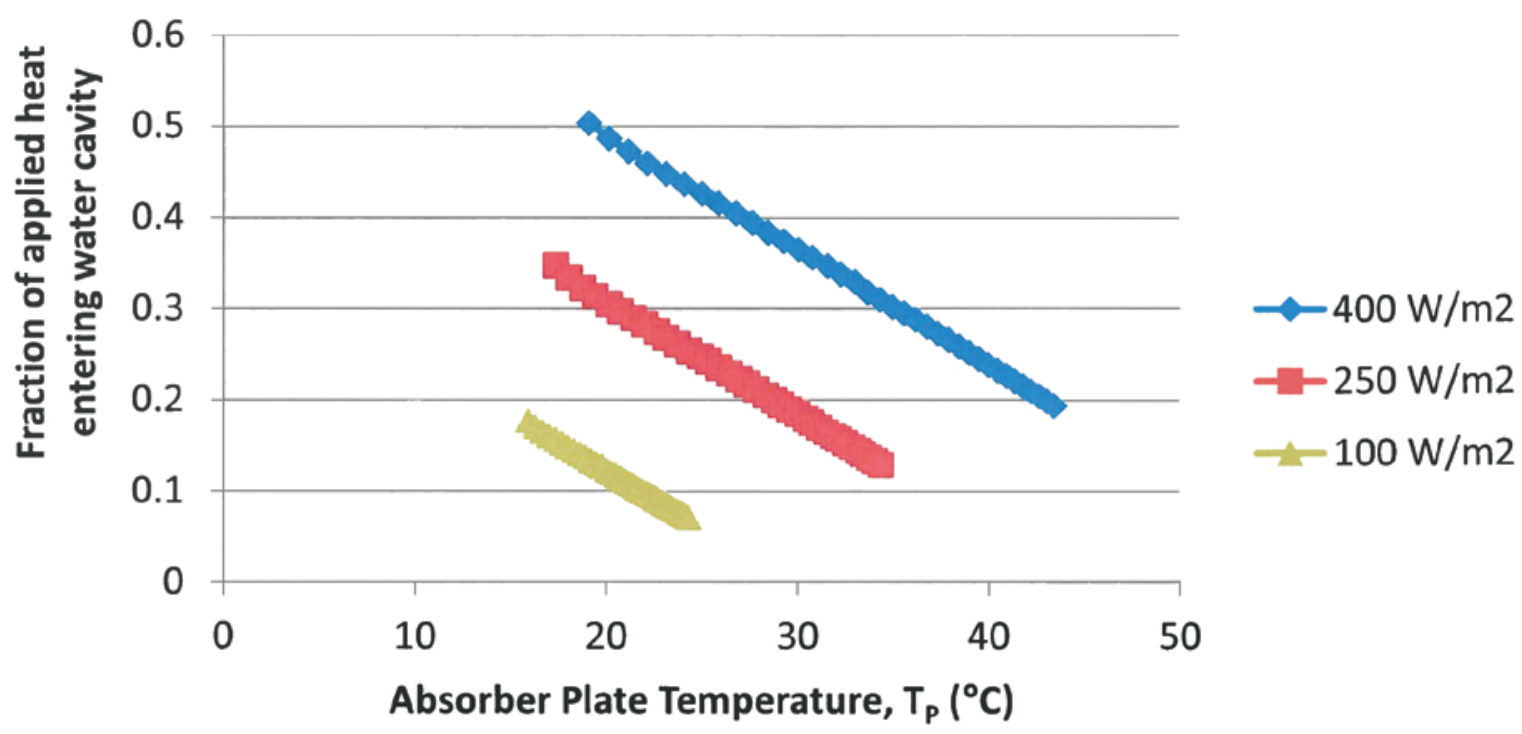

Figure 7: Fraction of applied heat entering water cavity VS Absorber plate temperature

The stratification formed during charging within the storage was also examined using the planes shown in Figure 8. The dimensionless temperature for planes within the ICS-SWH have been plotted for each hour during the charging simulation at $400 \mathrm{~W} / \mathrm{m}^{2}$. Additionally the equilibrium dimensionless temperature profiles for different applied heat fluxes have been plotted. The results are shown in Figures 9 and 10 whereby the evolution of stratification within the storage with time and for different heat fluxes is represented. Initially the storage shows limited stratification within the upper section of the cavity, marked by a notable drop in temperature beneath the fins. This is as a result of the conductivity of the draw-off manifold and fins which aid heat transfer from the absorber plate to the fluid and also act to conduct heat longitudinally through the cavity. As the flow regime develops within the storage, the stratification profile changes toward a more convex profile, with a significant decrease in temperature persistent toward the base of the storage. As expected the level of stratification increases with applied heat flux. 


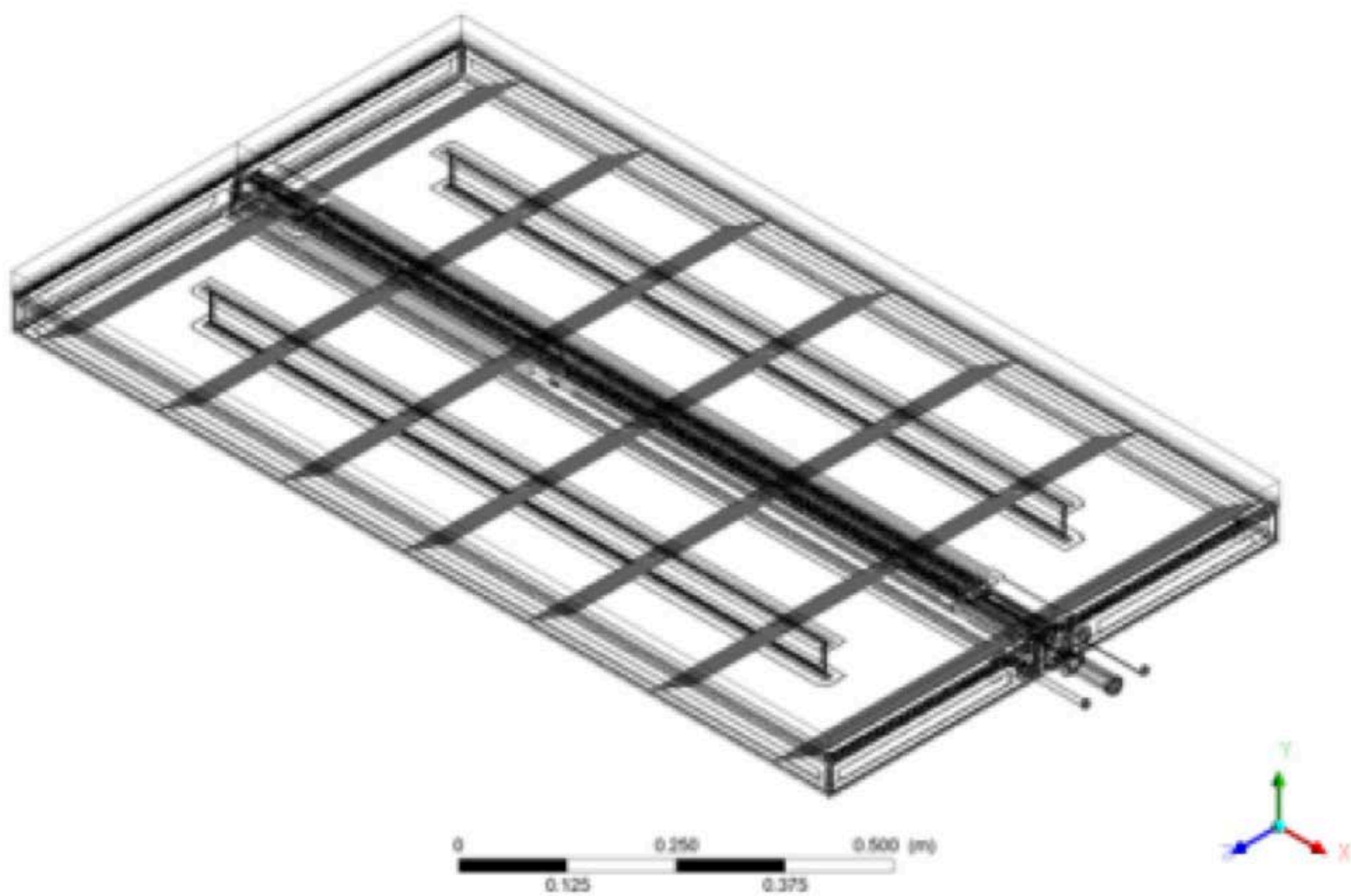

Figure 8: Location of planes for stratification study

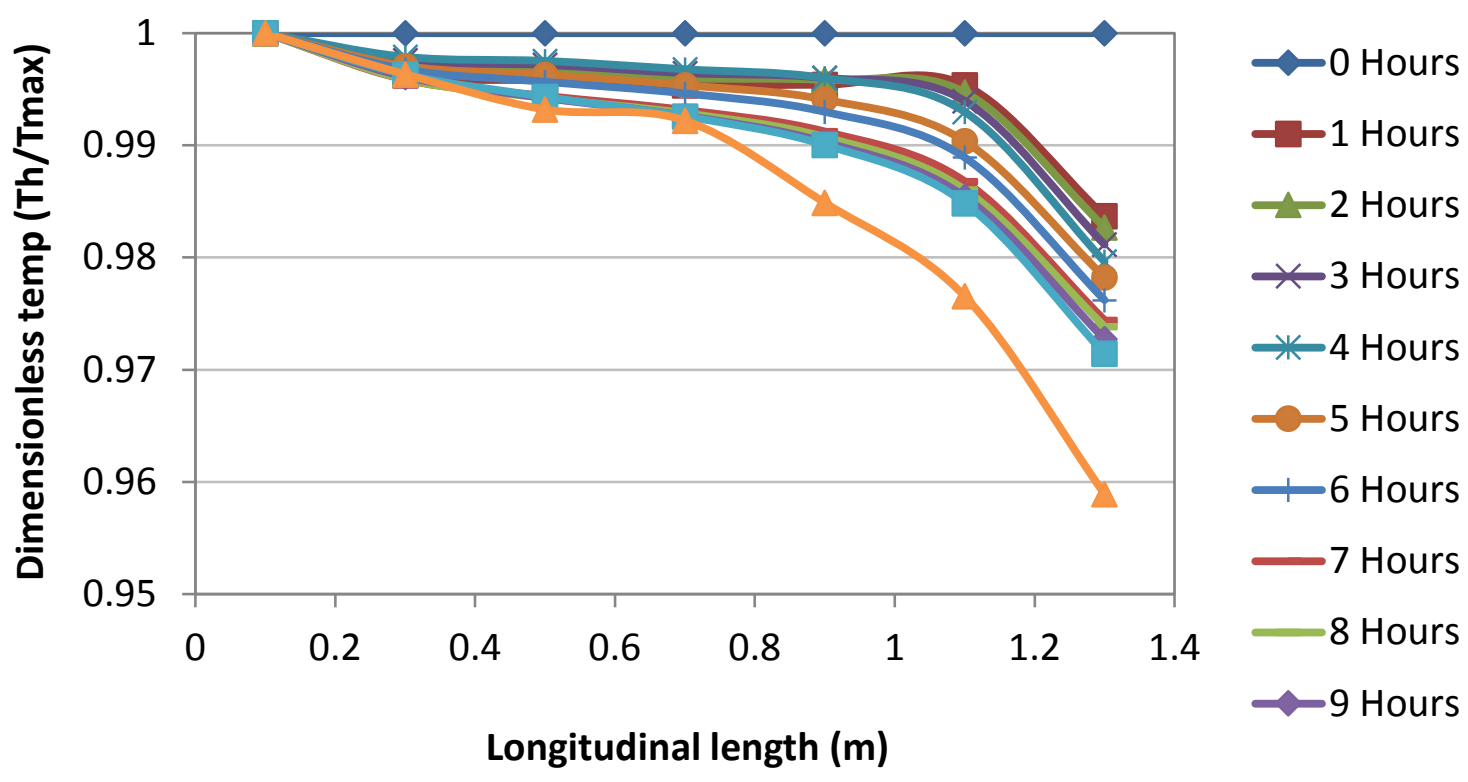

Figure 9: Stratification development with $400 \mathrm{~W} / \mathrm{m}^{2}$ 


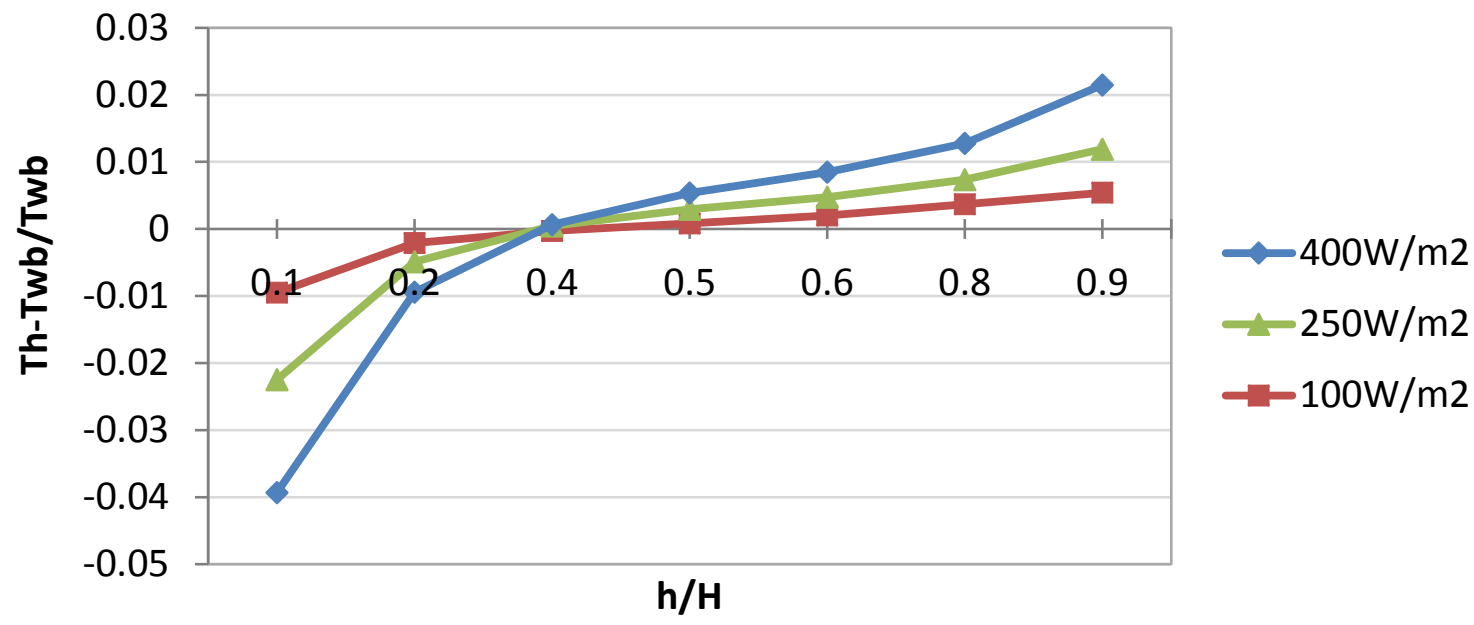

Figure 10: Dimensionless temperature stratification after $8 \mathrm{hrs}$ of operation

Figure 11 shows the temperature distribution at the surface of the storage for each applied heat flux after 8 hours of operation. The temperature distribution is shown to have significant variations longitudinally as a result of the fins and draw-off manifold. The reduction in insulation effectiveness surrounding the inlet and outlet penetrations is also highlighted, suggesting the potential for design improvement in these areas.

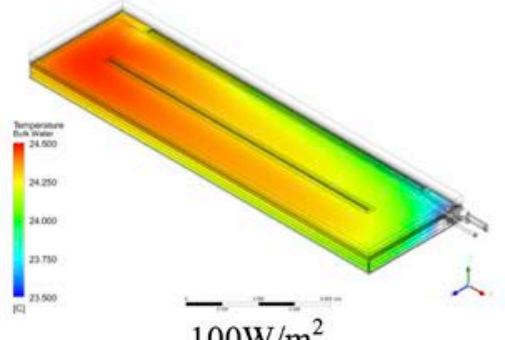

$\overline{100 \mathrm{~W} / \mathrm{m}^{2}}$

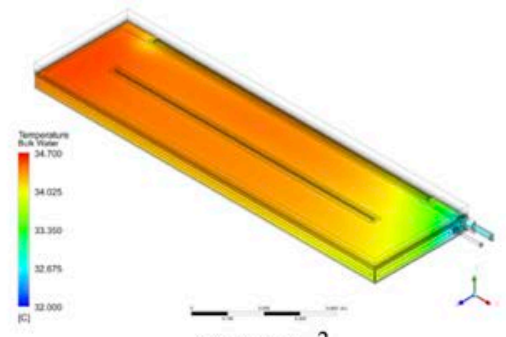

$250 \mathrm{~W} / \mathrm{m}^{2}$

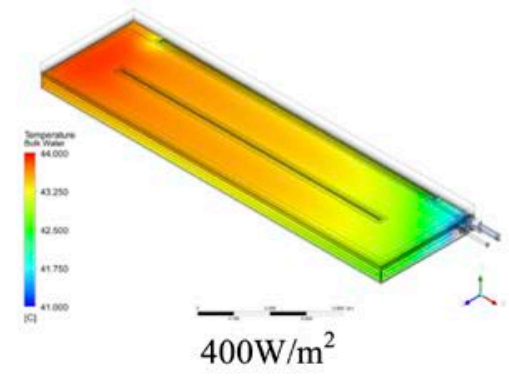

Figure 11: Water cavity temperature at 8 hrs constant heat flux

Figure 12 shows a cross-section of the storage cavity, absorber plate and aluminium tank of the ICS-SWH taken at the longitudinal midpoint at 4 hours of $250 \mathrm{~W} / \mathrm{m}^{2}$ applied heat flux. This clearly shows the effect of the fins, which form protrusions from the absorber plate into the cavity. By effectively increasing the surface area of the absorber plate, the overall heat transfer improved at the expense of thermal stratification within the storage by encouraging strong longitudinal currents to form near walls. This brings colder water from the lower section of the ICS-SWH to the upper heated surface increasing the localised temperature difference and hence increasing the heat transfer rate. 

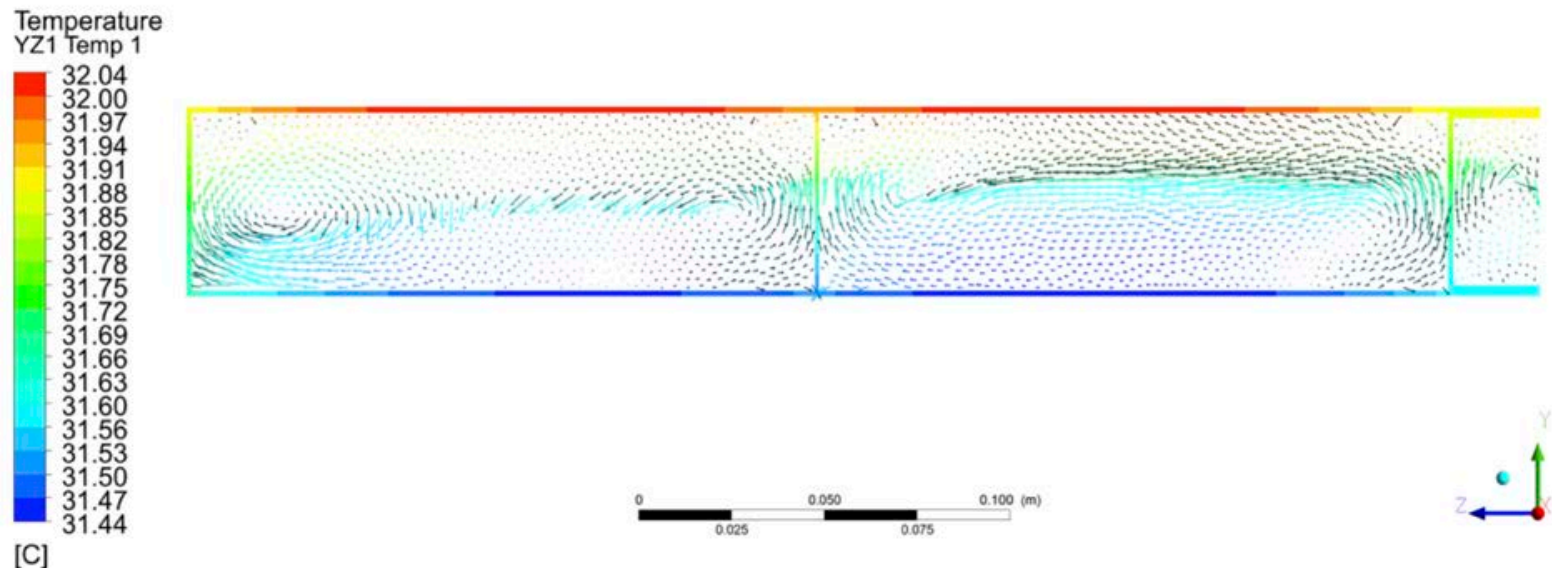

Figure 12: Contours and velocity vectors of temperature at midplane for $250 \mathrm{w} / \mathrm{m}^{2}$ at $4 \mathrm{hrs}$

\subsubsection{Draw-Off}

The analysis of the draw-off characteristics of the ICS-SWH, was performed by examining the temperature development with time. Figure 13 shows some interesting trends becoming apparent: as a result of the configuration of the draw-off manifold when not applying auxiliary heat, the temperature of the water leaving the ICS-SWH is fractionally higher at a higher flow rate. This effect is because less heat is transferred from the water in the draw-off manifold to the cooler water at entering the base of the storage.

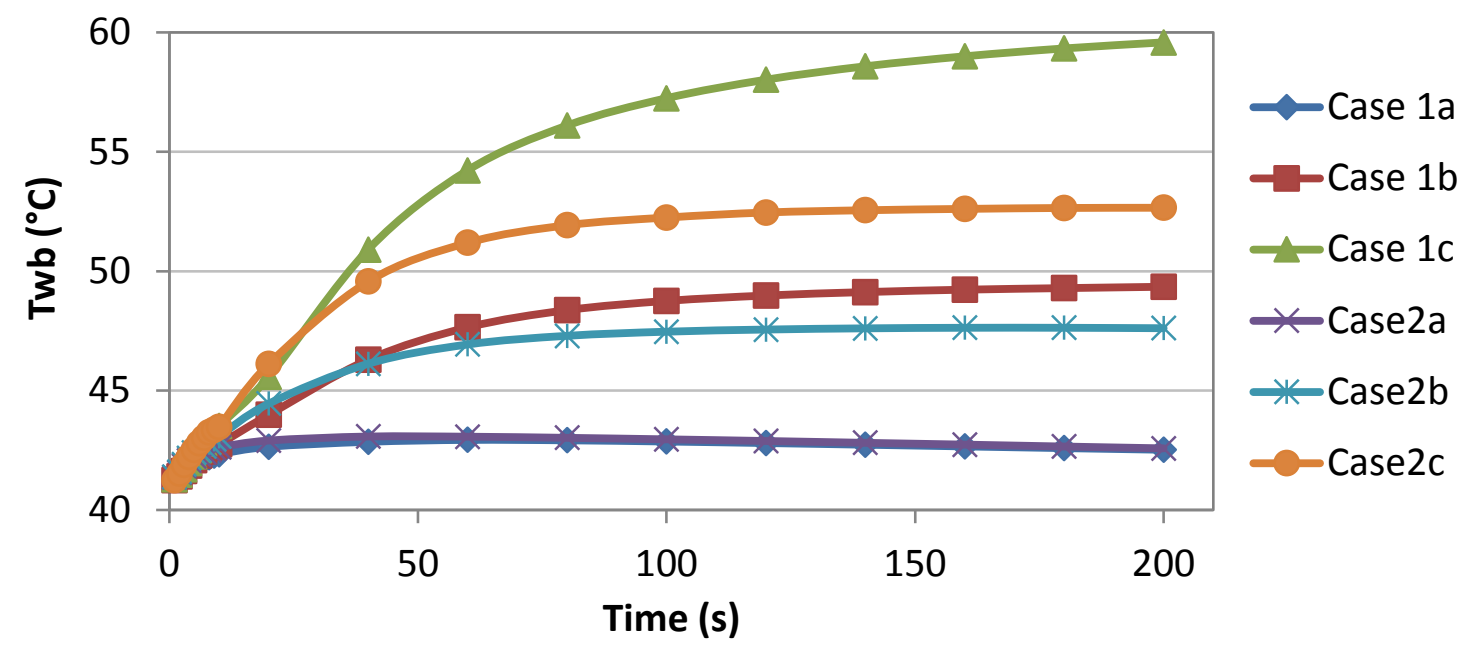

Figure 13: Draw off water cavity bulk temperature

Figure 14 shows the efficiency curves of the element for each of the cases specified in Table 4. These results show that the efficiency of the heating element improves significantly at higher rates of additional heat, and also favour higher flow rates. This effect is created because heat is more effectively removed from the surface of the 
heater as the velocity of the water traversing it increases, leading to increasingly higher Reynolds numbers and turbulent effects.

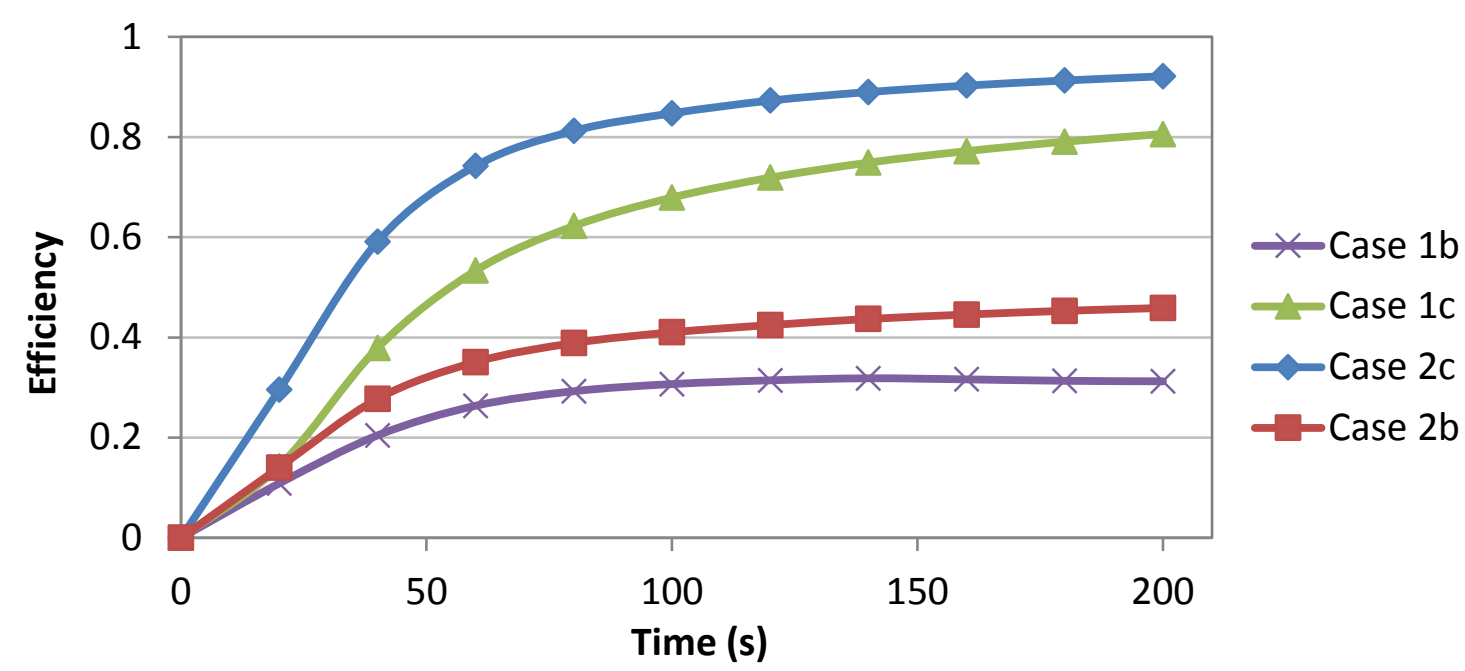

Figure 14: Auxiliary heater efficiency

Key results of all the draw-off cases are summarised in Table 2. Case 1 drew 51\% of the total mass of water of Case 2 and therefore some initial comparisons can be made. When no additional heating is applied, the energy delivered is comparable. This raises the potential of an alternative configuration for the ICS-SWH. Though the initial concept would have been to have multiple units delivering drawn-off water at a low flow rate, these results raise the possibility of a revised configuration with individual units drawing off at a higher rate when required. Pursuing this avenue of research is supported by the increased efficiency of the auxiliary heating with higher flow rates and the ratio of energy delivered between Cases 1a and 2a matching that of the ratio between mass drawn-off. Note that the auxiliary heating is part of the total energy use and hence its efficiency has a bearing on the energy budget.

Table 2: Draw off case summary

\begin{tabular}{|lllll|}
\hline Case & $\begin{array}{l}\text { Aux heat } \\
(\mathbf{k W})\end{array}$ & $\begin{array}{l}\text { Draw-off } \\
\text { duration } \mathbf{( s )}\end{array}$ & $\begin{array}{l}\text { Mass drawn- } \\
\text { off }(\mathbf{k g})\end{array}$ & $\begin{array}{l}\text { Energy } \\
\text { delivered }(\mathbf{k J})\end{array}$ \\
\hline 1a & 0 & 200 & 6.57 & 838.24 \\
2a & 0 & 200 & 12.81 & 1637.25 \\
1b & 1.5 & 200 & 6.57 & 1026.21 \\
2b & 1.5 & 200 & 12.81 & 1907.27 \\
1c & 3.0 & 200 & 6.57 & 1308.77 \\
2c & 3.0 & 200 & 12.81 & 2178.42 \\
\hline
\end{tabular}

When examining the performance of the inlet manifolds for both draw-off rates Figure 15 shows the velocity streamlines within the ICS-SWH during draw-off, showing an even distribution and profile throughout the main body of the storage. Figure 16 provides an indication of the state within the ICS-SWH immediately following a draw-off event for both Cases $1 \mathrm{a}$ and $2 \mathrm{a}$. Here the internal disruption to the storage is shown to be small with limited mixing between the newly introduced 
cold water and existing water. This provides a clear advantage when drawing off, maximising the immediate availability of heated water.

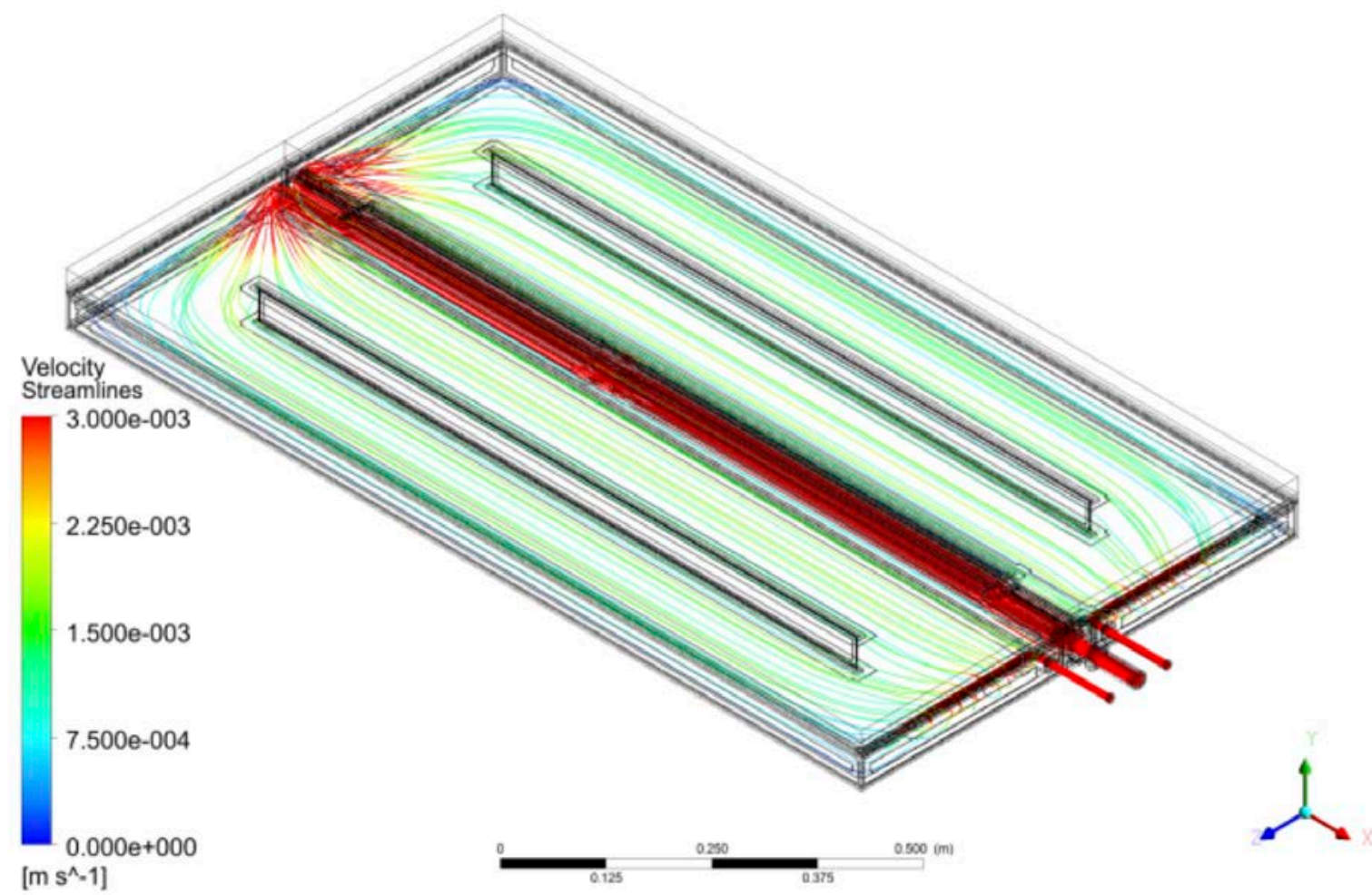

Figure 15: Streamline of velocity during draw off for case 1

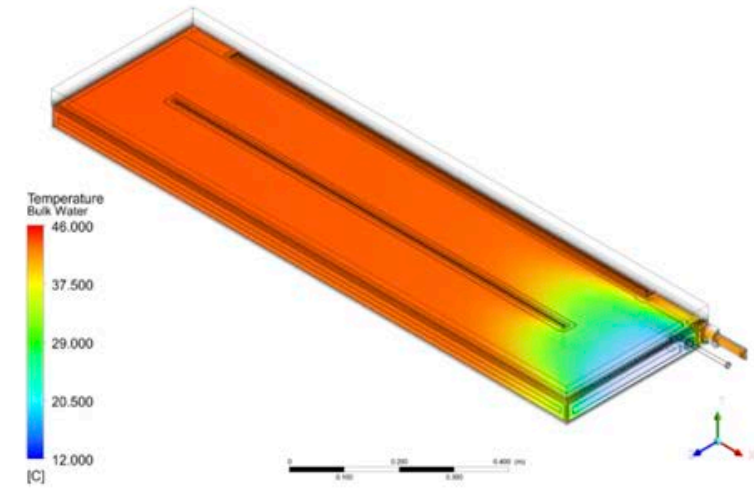

Case 1a

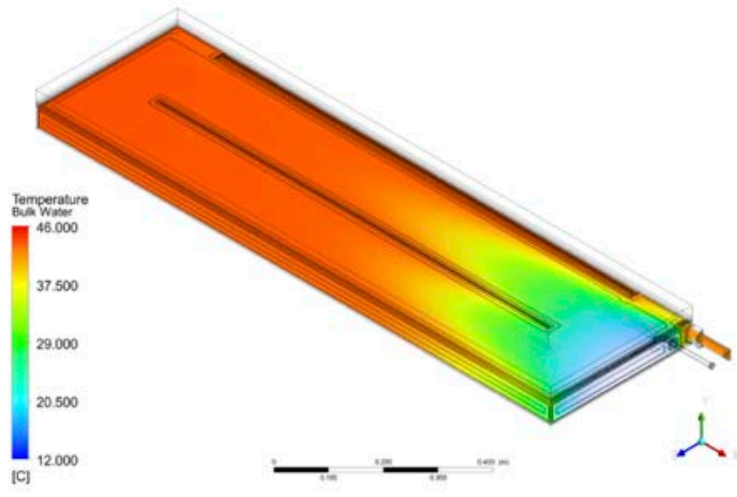

Case 2a

Figure 16: Water Cavity temperature rendering following discharge

\subsubsection{Recharging}

The characteristics of the ICS-SWH when recharging were assessed against the two draw-off test cases with no auxiliary heat input. After an hour of applied heat flux the internal temperature distribution is as shown in Figure 17. This clearly shows the ability of the ICS-SWH design to retain high levels of stratification, with limited mixing between the hot and cold bodies of water. 


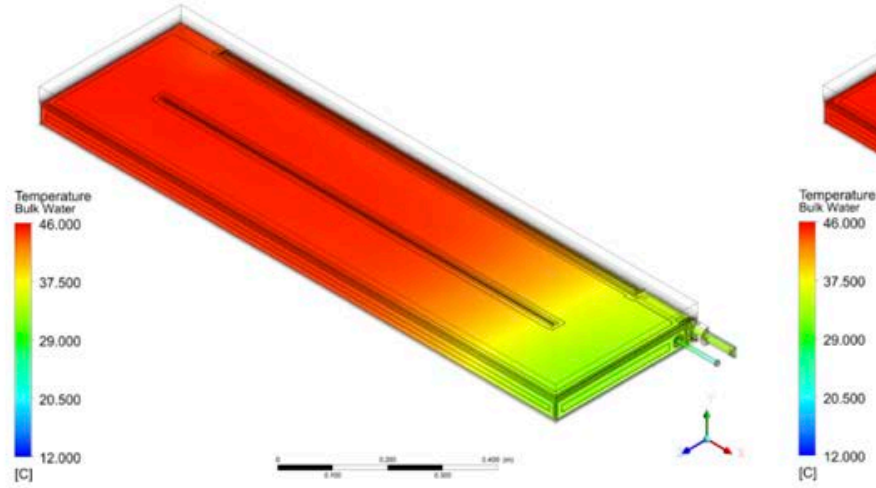

Case 1a

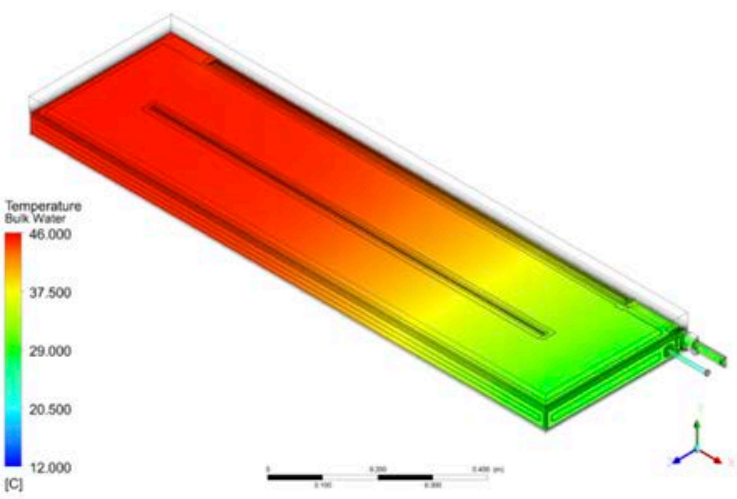

Case 2a

Figure 17: Water cavity temperature render at $1 \mathrm{hr}, 400 \mathrm{~W} / \mathrm{m}^{2}$ recharging

To provide a benchmark for recovery from draw-off a new case was developed, Case 3, where no draw-off occurred and heat flux was applied continuously to a charged tank at $400 \mathrm{~W} / \mathrm{m}^{2}$ for the duration of the draw-off and recharging cycles. When examining the rate of recharge against time, Figures 18 and 19 show the faster recovery of Case $2 \mathrm{a}$. This is as a result of the greater thermal energy difference introduced, driving higher rates of thermal transfer from the absorber plate to the storage. Though the bulk temperature difference at the start of the recharging period is approximately $4^{\circ} \mathrm{C}$ this has reduced to $2 \cdot 1^{\circ} \mathrm{C}$ by the end of the period.

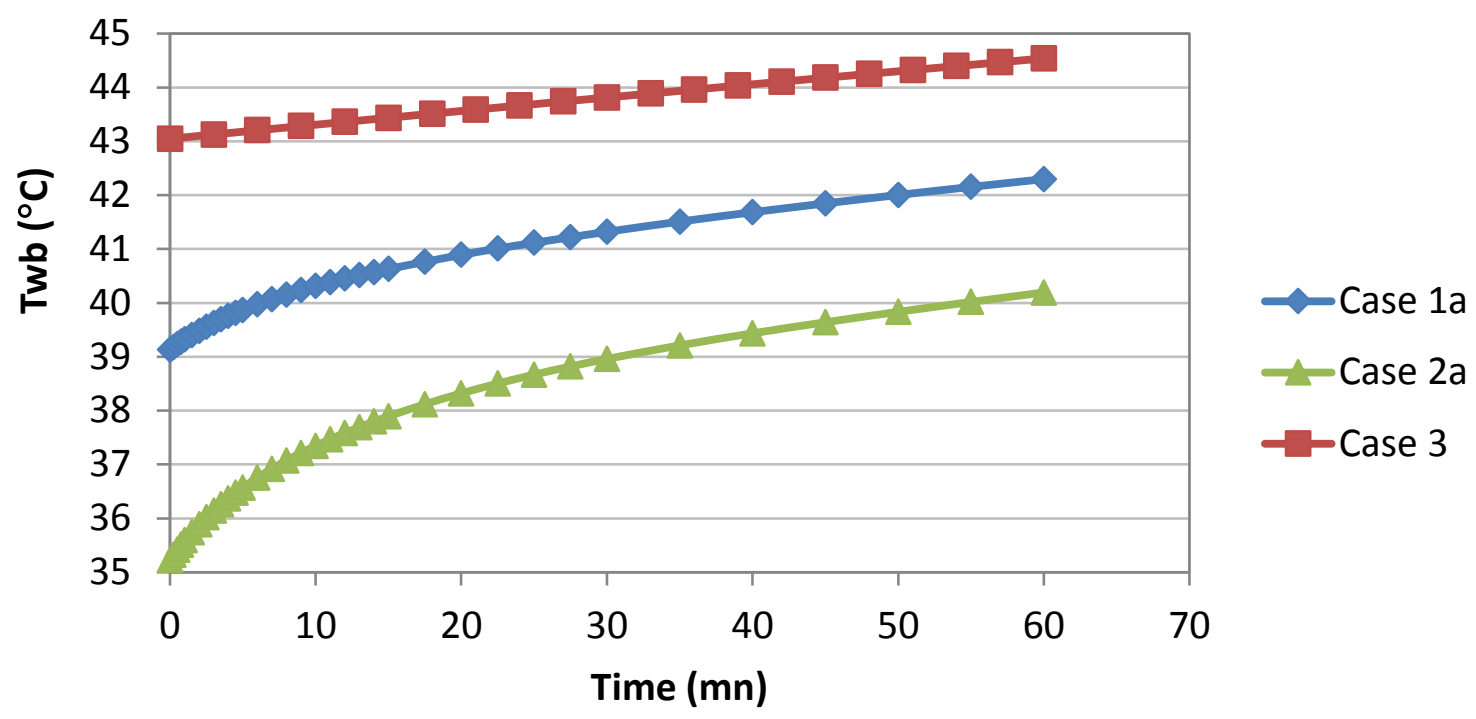

Figure 18: Water cavity bulk temperature: Recharging from draw-off cases at $400 \mathrm{~W} / \mathrm{m}^{2}$ 


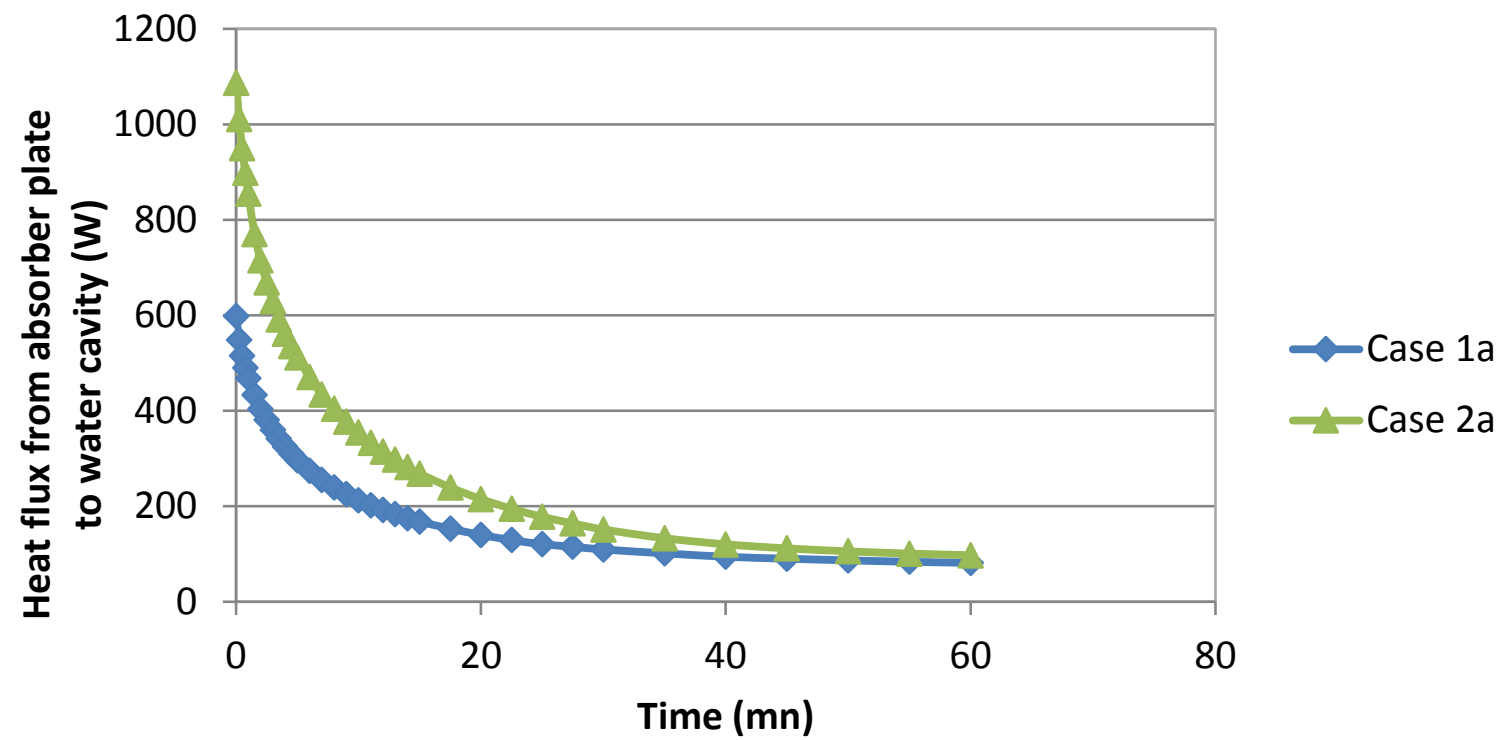

Figure 19: Heat flux from absorber plate to water cavity: Recharging from draw-off cases at $400 \mathrm{~W} / \mathrm{m}^{2}$

When comparing the relative rates of recovery, it is useful to examine the energy present within the collector, and the gain following a period of recharging. To analyse this, the heat energy within the storage above the inlet temperature is presented in Table 3.

Table 3: Heat energy in storage during recharge cycle

\begin{tabular}{|lrrr|}
\hline Case & Start (kJ) & End $(\mathbf{k J})$ & Gain (kJ) \\
\hline $1 \mathrm{a}$ & 5329 & 5952 & 622 \\
$2 \mathrm{~b}$ & 4564 & 5538 & 974 \\
3 & 6099 & 6392 & 292 \\
\hline
\end{tabular}

These results reinforce the potential viability of using single units at higher draw-off rates to provide maximum utility to the end user. In a hypothetical scenario with 2 ICS-SWH units a required draw-off could be met either by both (case 1a) or by a single unit (case $2 a$ ) while the other remains in a charging state (case 3 ). Both configurations would supply a similar amount of energy during draw-off and after an hour long recharging period would contain similar amounts of energy (11.9MJ vs 11.93MJ).

\subsubsection{Cooling}

The heat loss coefficient ( $U$-Value) has traditionally been considered as a constant for SWH. However, as the heat loss from the storage during cooling is primarily driven by radiative and convective losses to sky and ambient air respectively, it follows that it is essentially a function of temperature. The derived heat loss coefficient was calculated and is illustrated Figure 20. The results for each case initially show the regime transfer within the ICS-SWH as it undergoes change from charging to cooling. Once this has developed, the relationship between heat loss and 
absorber plate temperature becomes linear. The results fall in line with the findings of other research [4] with the exception of the observed reduction in thermal performance at higher stratification levels. This can be attributed to a number of differing factors between the studies such as: the empirical tests introduced a silicon heating pad increasing the thermal resistance of the unit, and significantly reducing radiative losses; and the lack of fins present in the ICS-SWH studied [4] increasing the initial stratification within the collector.

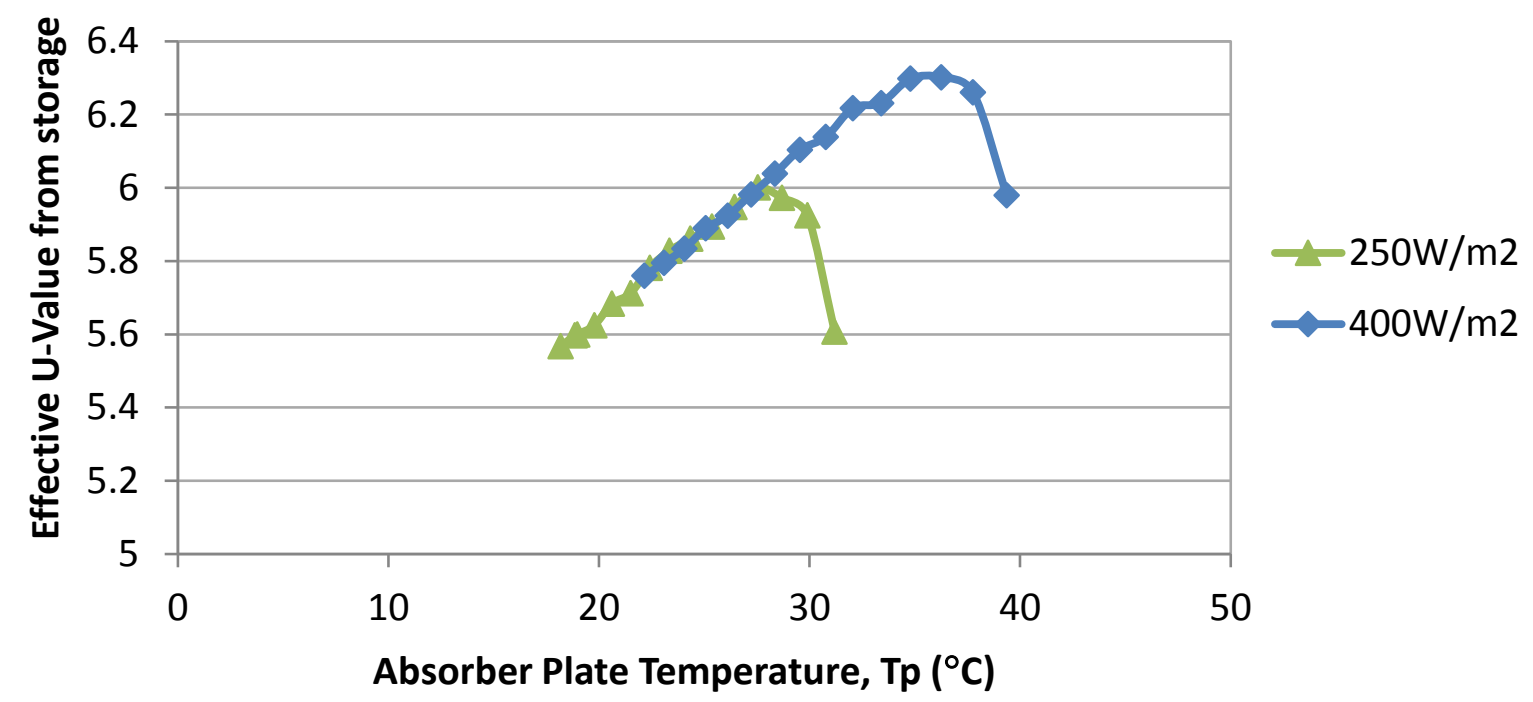

Figure 20: Effective U-Value from storage for different plate temperatures and starting states

\subsubsection{Auxiliary heating of storage}

The results from the $250 \mathrm{~W} / \mathrm{m}^{2}$ cooling test were used as a starting point, with two differing rates of auxiliary heat added to the storage. The bulk temperature rise with time is presented in Figure 21.

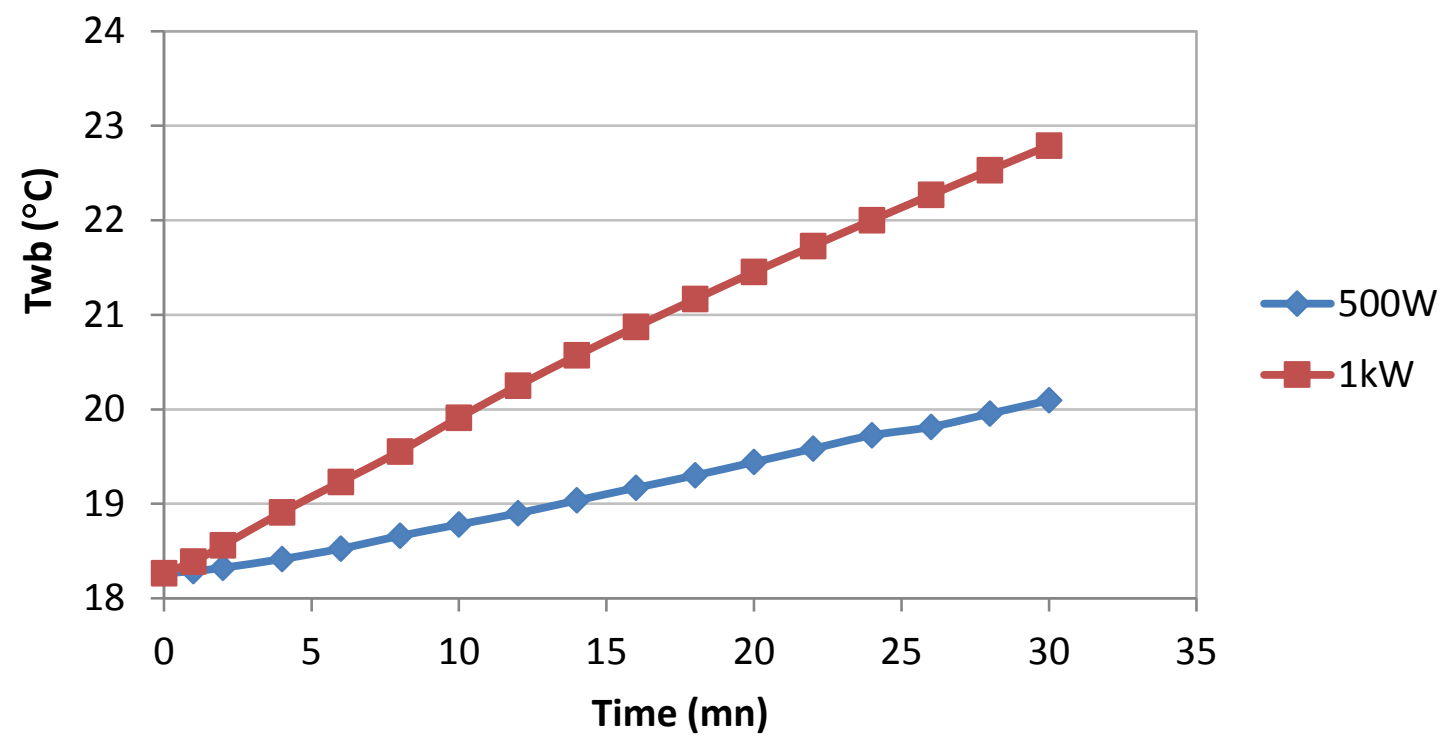

Figure 21: Water cavity bulk temperature rise within storage with differing rates of auxiliary heat 
Figure 22 shows the efficiency curves of each auxiliary heat input. The initial efficiency of the higher input is significantly greater, as a direct consequence of the larger convective currents formed within the storage cavity, encouraging mixing and distributing heat more effectively throughout the ICS-SWH. At the lower rate of heat input the smaller convective flow outside of the draw-off manifold results in much greater thermal gradients across both the storage cavity and absorber plate. This scenario results in greater losses to the atmosphere being experienced from the absorber plate above the heater, and consequent lower efficiency.

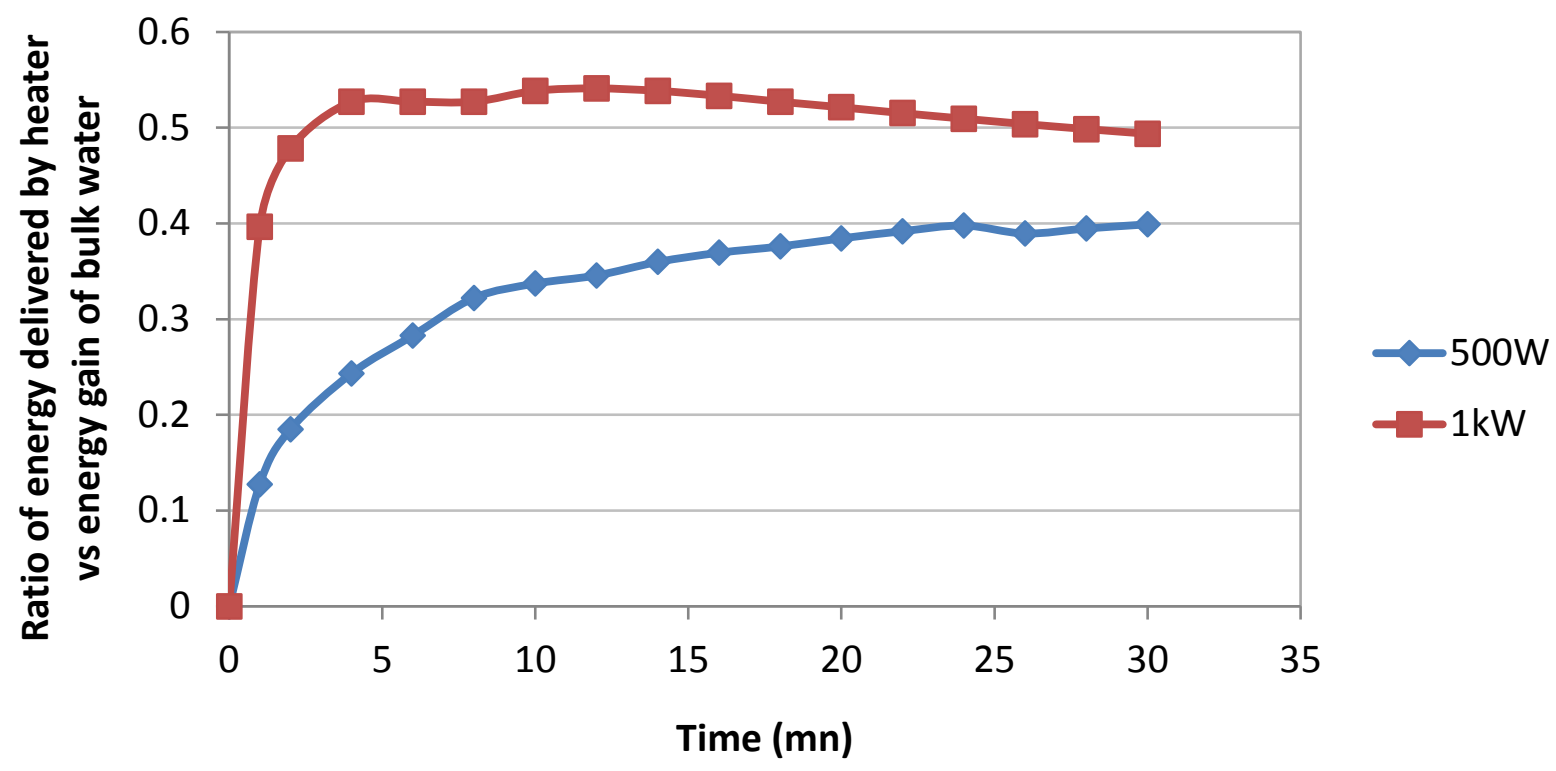

Figure 22: Efficiency of storage auxiliary heater

\subsection{Experimental results}

The resultant values for the bulk water temperatures, Twb, obtained empirically and numerically for all tested heat fluxes are presented in Figure 23 to examine the validity of the simulation. This shows an acceptable correlation between the CFD simulation and the experiment with a slope of the best-fit line of 0.93 and a coefficient of determination, $\mathrm{R}^{2}$, of 0.95 suggesting the fairly good capability of the predictive model. The average absolute deviation of temperature difference between the CFD simulation results and the measurements is $7.3 \%$. It was observed in Figure 23 that CFD tends to overestimate the temperature for low heat fluxes while underestimating it for higher heat fluxes and when increased time of exposure occurs. The discrepancies between the measurements and the CFD model could be 
due to a number of reasons such as: a. construction related factors, b. assumptions related factors, c. experimental related factors.

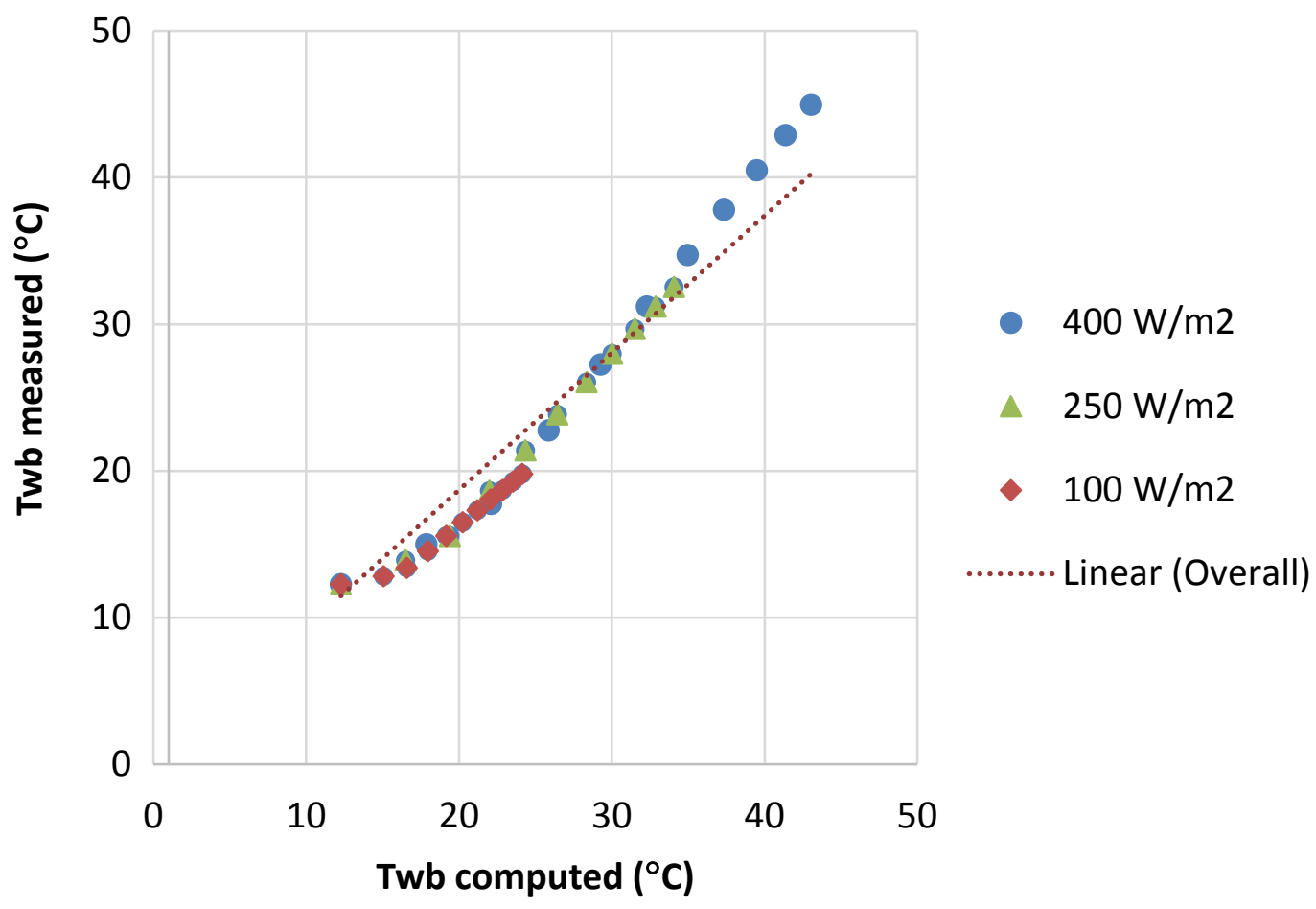

Figure 23: Empirical and numerical bulk water temperature comparison

Further analysis was undertaken for a $400 \mathrm{~W} / \mathrm{m}^{2}$ heat flux using different statistical indicators presented in Table 4. The slope of the best-fit line between the measured and computed variable was found to be 0.99 with a $\mathrm{R}^{2}$ of 0.95 indicating a slight over estimation with an acceptable unexplained variation. The total mean bias error (MBE) of -0.8 shows that the CFD model has an overall tendency to over-predict its computed values by about 0.8 degree Celsius temperature. The hourly MBE analysis showed that the model has a tendency to over-predict its modelled values up to 6 hours of the heat applied with significant deviation within the first 3 hours of simulation and then under predict it. The root mean square error, RMSE, shows the strength of linear correlation between two variable. Its value of 2 suggest a poor ability of the model to predict the ICS-SWH water bulk temperature. However, in this instance, the high value of RMSE can be due to the presence of small number of high error predictions in the early hours of the simulation (first 3hrs).

Table 4: Statistical indicators $-400 \mathrm{~W} / \mathrm{m}^{2}$

\begin{tabular}{|ll|}
\hline Statistical indicator & Values \\
\hline Slope & 0.99 \\
R2 & 0.95 \\
MBE $\left({ }^{\circ} \mathrm{C}\right)$ & -0.8 \\
RMSE $\left({ }^{\circ} \mathrm{C}\right)$ & 2 \\
\hline
\end{tabular}


To allow comparison between the original and new ICS-SWH configurations Figures 25 and 26 present the key performance differences between each configuration. Figure 25 presents the energy storage efficiency of the ICS-SWH configurations when exposed to $400 \mathrm{~W} / \mathrm{m}^{2}$ heat flux against the dimensionless temperature difference between the bulk water temperature, Twb, and the absorber plate, Tp, above the ambient environment, Ta. This demonstrates the higher energy storage efficiency of the new design, especially at greater temperature differentials between the absorber plate and water bulk temperature. This phenomenon will be greatest, both at the beginning of a charging cycle, or following draw-off. As the temperature ratio tends toward unity, the energy storage efficiency correspondingly tends toward 0 as the system approaches equilibrium, where the losses from the water storage match the energy gains. In this example the water bulk equilibrium temperature is $6.3^{\circ} \mathrm{C}$ higher for the new ICS-SWH configuration. Figure 24 also shows the heat loss rate from the storage when cooling from a bulk temperature of $50^{\circ} \mathrm{C}$ and an ambient temperature of $10^{\circ} \mathrm{C}$. Here a higher rate of cooling is exhibited by the new ICS-SWH design; this is in-line with the expected characteristics of the new ICS-SWH, where a higher aspect ratio results in greater convective currents within the storage and hence a greater rate of heat-transfer. This effect can also be attributed to the greater rate of heat retention during storage as it is distributed throughout the cavity more effectively.
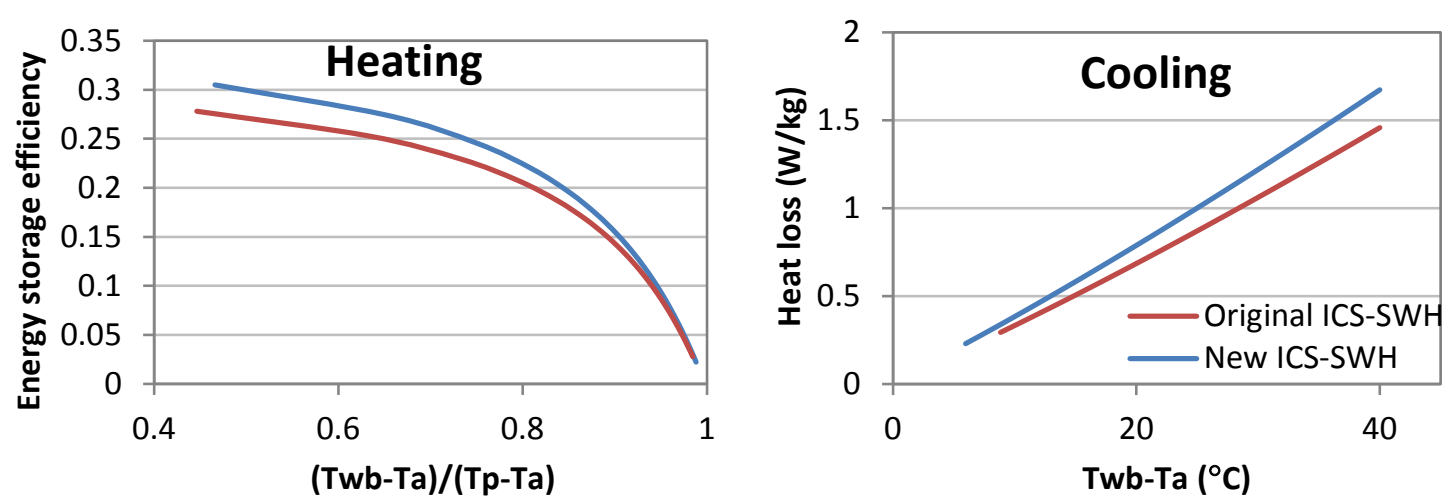

Figure 24: Energy storage and loss rates during heating, at $400 \mathrm{~W} / \mathrm{m}^{2}$, and cooling cycles

The comparative performance of the new and original ICS-SWH configurations is illustrated in Figure 25, showing the bulk water temperature rise for the 10 hours of heating followed by cooling toward ambient. This clearly demonstrates the relative performance characteristics between the configurations. The new ICS-SWH shows significantly improved heat storage during charging, which is traded off against a reduced heat retention ability during cooling. At its peak the bulk water temperature is $6.3^{\circ} \mathrm{C}$ higher in the new configuration; following 11 hours of cooling, the temperatures in each configuration reach equality. 


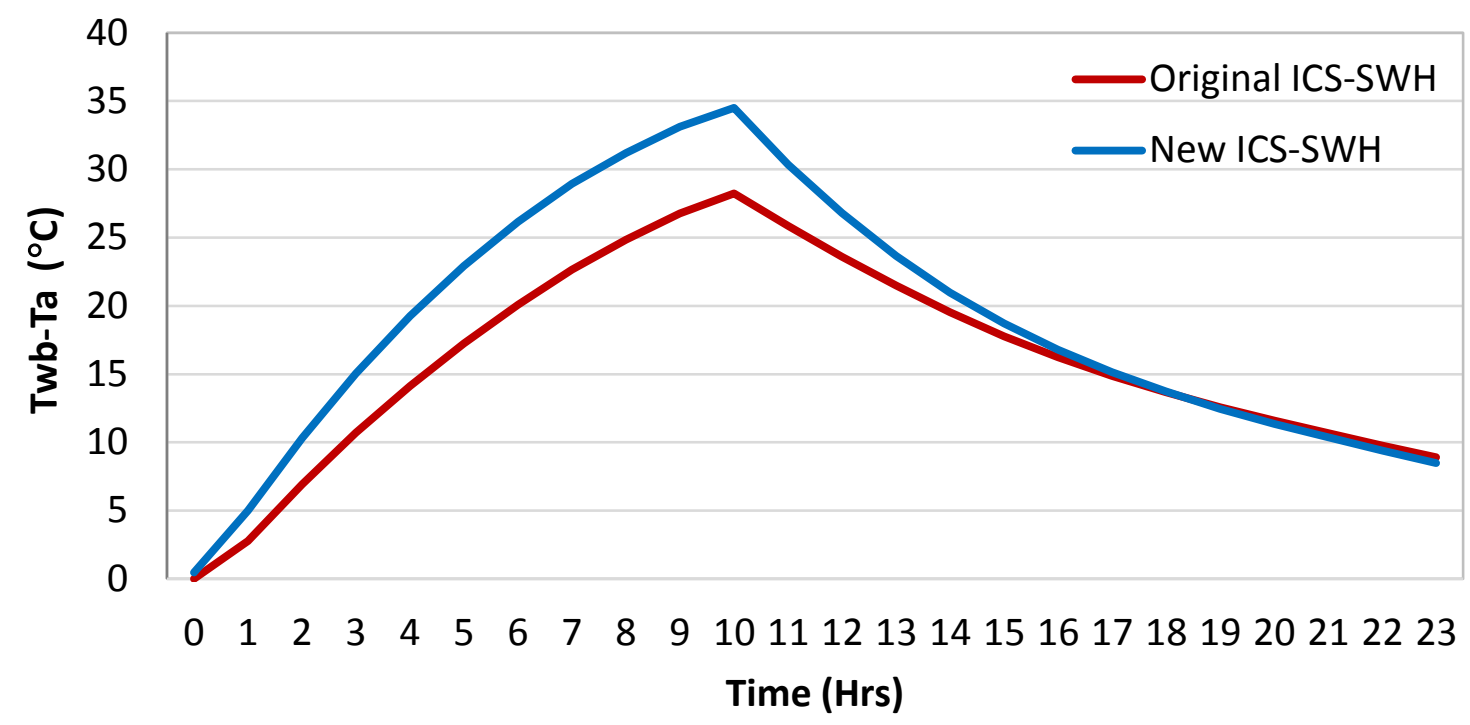

Figure 25: Test cycle results for new and original ICS-SWH configurations at $400 \mathrm{~W} / \mathrm{m}^{2}$

In order to evaluate temperature stratification, the temperature profiles along the original and new systems dimensionless height were plotted as shown in Figure 26. These results showed that the new system has improved thermal stratification as it achieved higher temperature at the top nodes of the storage tank while keeping a low temperature at the bottom.

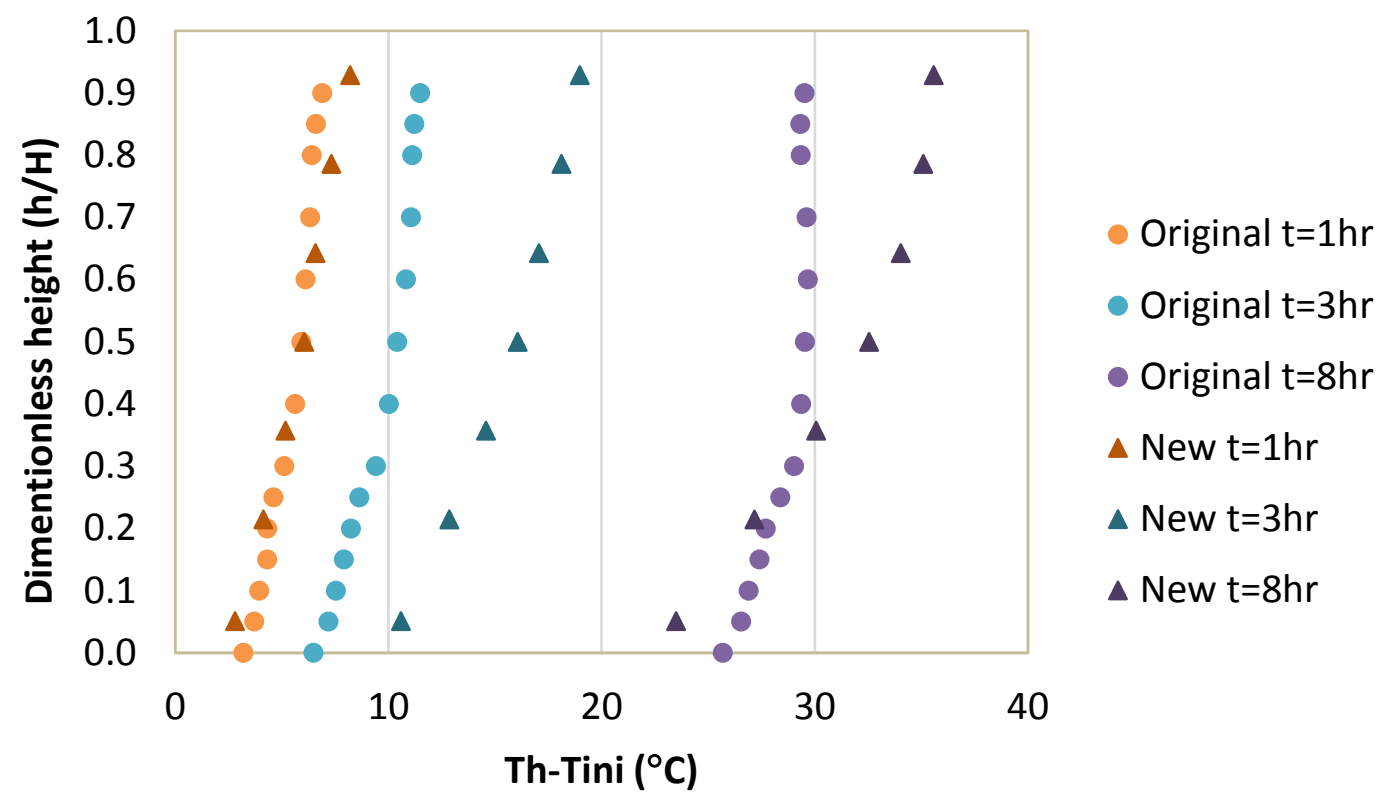

Figure 26: Temperature stratification profiles along the cavity height at $400 \mathrm{~W} / \mathrm{m}^{2}$

Figure 26 shows a significant increase in stratification and overall water bulk temperatures within the collector compared to the previously studies ICS-SWH [5] with sharp increases until the system approaches equilibrium (8hrs). Based on these profiles it is possible to determine the temperature difference in the tank at a given 
time. After 1, 3, and 8hrs of charge, percentage of increase in stratification between the previous and new collectors were found at $31 \%, 45 \%$ and $133 \%$ respectively.

\section{Conclusions}

This paper identifies the need to better integrate ICS-SWHs in building design and the inherent geometric design constraints when considering their integration in roofstructures. A combined experimental-numerical analysis of a new ICS-SWH system is presented in this paper. The novel prototype aims to improve upon existing ICSSWH designs by optimising its geometry for integration within a SIP roof system with minimal structural impact and improving the integration between the SWH and an auxiliary water heater. The experimental results demonstrate that in the present configuration the ICS has a reasonable performance in comparison with previous researched collectors with an increase in bulk temperature of $6.3^{\circ} \mathrm{C}$ and a maximum and average percentage increase in temperature stratification from the original to the new collector of $67 \%$ and $133 \%$ respectively (after 8 hrs of charging). The results clearly demonstrate the robustness of the thermal network solver, and its ability to be adapted to new configurations of ICS-SWH. The increased aspect ratio of the new ICS-SWH however showed to significantly alter the heating and cooling characteristics of the $\mathrm{SWH}$, both gaining and loosing heat at a greater rate than the original design. This is caused by higher convective flow regimes generated within the storage. In order to gain more insight of the newly developed ICS-SWH behaviour a CFD analysis was undertaken. The numerical analysis demonstrates that the new ICS-SWH charges effectively, with some stratification. However, this was found to be reduced in comparison to previous studies, as a result of geometric changes and the increased thermal conductivity of internal elements of the storage (fins and outlet manifold). Both CFD and experimental results showed the influence of solar irradiance and the importance of stratification in maximising temperature outputs.

Very few studies have looked into the impact of draw-off flow rates on the magnitude of the cooling in such application. This was thus undertaken through a CFD simulation of the considered geometry to examine the expected designed performance of the collector. It was shown that as a consequence of the unit's drawoff manifold design, and the stratification both present in the storage and further induced by the influx of unheated water, some cooling of the draw-off became inevitable. The magnitude of this cooling reduces at higher draw-off rates resulting in higher temperatures at the outlet for the volumes drawn-off, providing better energy delivery efficiency. The cooling performance of the current design has been assessed, and some insights into the operation of the auxiliary heater have been gained. These indicate greater efficiency at higher output as a result of the larger convective currents within the storage, while at lower levels large amounts of heat are lost from the top of the panel. The analysis showed that while the new ICS-SWH 
showed to have reasonable performance in supplying hot water during the discharge phase, improvements in the efficiency of the ICS are desirable.

\section{References}

[1] Smyth, M., Norton, P.C and Eames, B. (2001a) Evaluation of a freeze resistant integrated collector/storage solar water-heater for northern Europe. Applied Energy, 68, pp. 265-268.

[2] Smyth, M., Eames, P., Norton, B. (2001b) Annual performance of heat retaining integrated collector/storage solar water heaters in a northern maritime climate. Solar Energy, 70 (5) pp.391-401

[3] Garg H.P. and Rani, U. (1982) Theoretical and experimental studies on collector/storage type solar water heater. Solar Energy, 29, pp.467-478.

[4] Junaidi, H. (2009) Optimized solar water heater for Scottish conditions: Edinburgh Napier University, 2009.

[5] Garnier, C. (2009) Performance Measurment and Mathematical Modeling of Integrated Solar Water Heaters. Edinburgh: Edinburgh Napier University.

[6] MacGregor A.W.K and Balmbro D. (1984) Why North is best for solar heating of building? Where are the best places in Scotland for solar space heating?, in NorthSun84: International Conference on Solar Energy at High Latitudes, 1984, p. 76.

[7] Scottish Government. (2009) Renewables Action Plan. <http://www.scotland.gov.uk/Publications/2009/07/06095830/15>

[8] Hill, F., Lynch, H. and Levermore ,G. (2011) Consumer impacts on dividends from solar water heating. Energy Efficiency, 4 (1) pp. 1-8.

[9] Energy Saving Trust (2011) Here comes the sun: a field trial of solar water heating systems, London.

[10] Hestnes, A.G. (1999) Building integration of solar energy systems. Solar Energy, pp. pp.181-187

[11] Munari Probst, M.C. and Roecker, C. (2007) Towards an improved architectural quality of building integrated solar thermal systems (BIST), Solar Energy, 81, pp. pp.1104-1116

[12] Buker, M.S. and Riffat, S.(2015) Building integrated solar thermal collectors - A review. Renewable and Sustainable Energy Reviews, 51, pp. 327-346.

[13] HM Treasury (2015) Spending review and Autumn statement $<$ https://www.gov.uk/government/topical-events/autumn-statement-andspending-review-2015 >.

[14] Smith, S. Hairstans, R. MacDonals, R., Sanna, F. (2012) Strategic Review of the Offsite Construction Sector in Scotland, The Scottish Government, ISBN 978-178256-394-5

[15] Smith, R.S. (2015) Increasing role of offsite and advanced construction in the UK economy. CIAT Symposium. 'Architectural Technology: Design Futures Reflecting and Projecting'. December 2015. London. 
[16] Pokharel, N. (2003) Behaviour and design of sandwich panels subject to local buckling and flexural wrinkling effects. Queensland University of Technology.

[17] Chen, W. and Hao, H. (2015) Performance of structural insulated panels with rigid skins subjected to windborne debris impacts - Experimental investigations. Construction and Building Materials 77, pp.241-252.

[18] Medina, M.A., King, J.B. and Zhang, M. (2015) On the heat transfer rate reduction of structural insulated panels (SIPs) outfitted with phase change materials (PCMs). Energy, 33, pp. 667-678.

[19] Kosny J, Christian J. (2001) Whole wall thermal performance. Oak Ridge National

Laboratory.<www.ornl.gov/sci/roofs+walls/research/detailed_papers/Whole_Wall Therm/content.html >.

[20] Department of Energy (2003). Structural Insulated Panels. Office of Energy Efficiency and Renewable Energy.

[21] Souliotis, M., Singh, R., Papaefthimiou, S., Lazarus, I. J., Andriosopoulos, K. (2014) Integrated collector storage solar water heaters: survey and recent developments. Energy Systems, 7 (1) pp.49-72.

[22] Smyth, M., Eames, P.C., Norton, B (2006) Integrated collector storage solar water heaters. Renewable and Sustainable Energy Review, 10 (6) pp.503-538.

[23] Singh, R., Lazarus, I.J., Souliotis, M. (2016) Recent developments in integrated collector storage (ICS) solar water heaters: A review. Renewable and Sustainable Energy Reviews, 54, pp.270-298

[24] Kumar, R., Rosen,M.A. (2010) Thermal performance of integrated collector storage solar water heater with corrugated absorber surface. Applied Thermal Engineering, 30, pp.1764-1768.

[25] El-Sebaii, A.A. (2005) Thermal performance of a shallow solar pond integrated with a baffle plate. Applied Energy, 81, pp. 33-53.

[26] Chaurasia, P.B.L. and Twidell, J. (2001) Collector cum storage solar water heaters with and without transparent insulation material. Solar Energy, 70, pp.403-416.

[27] Reddy, K.S. and Kaushika, N.D. (1999) Comparative study of transparent insulation materials cover systems for integrated-collector-storage solar water heaters. Solar Energy Materials and Solar Cells, 58, pp.431-446.

[28] Prakash, J., Kaushik, S.C., Kumar, R., Garg, H.P. (1994) Performance prediction for a triangular built-in-storage solar water heater with transparent insulation. Energy, 19, pp.869-877.

[29] Ziapour, B.M. and Aghamiri, A.(2014) Simulation of an enhanced integrated collector-storage solar water heater. Energy Conversion and Management, 78, pp.193-203.

[30] Kaushik, S.C., Kumar, R., Garg, H.P.(1995) Effect of baffle plate on the performance of a triangular built in storage solar water heater. Energy Conversion and Management, 36(5), pp.337-342. 
[31] Ecevit, A., Wais, M.A.M.C., Al-Shariah, A.M. (1990) A comparative evaluation of the performances of three built-in-storage-type solar water heaters. Solar Energy, 44, pp. 23-36.

[32] Souza, J.V.D., Fraisse, G., Pailha, M., Xin, S. (2014) Experimental study of a partially heated cavity of an integrated collector storage solar water heater (ICSSWH). Solar Energy, 101, pp. 53-62.

[33] Swiatek,M., Fraisse,G., Pailha,M. (2015)Stratification enhancement for an integrated collector storage solar water heater (ICSSWH). Energy and Buildings, 106, pp.35-43.

[34] Sefa, T., Ahmet, S., Hakan, A.M. (2006) Temperature distributions in trapezoidal built in storage solar water heaters with/without phase change materials. Energy Conversion and Management, 47, pp.2143-2154.

[35] Bansal, N.K.and Buddhi, D. (1992) Performance equation of a collector-cumstorage system using phase change materials. Solar Energy, 48, pp.185-194.

[36] Tarhan, S., Sari, A., Yardim, M.H. (2006) Temperature distributions in trapezoidal built in storage solar water heaters with/without phase change materials. Energy Conversion Management, 47, pp.2143-2154.

[37] Al-Hinti, I., Al-Ghandoor, A., Maaly, A., Naqeera, I.A., Al-Khateeb, Z., Al-Sheikh, O.(2010) Experimental investigation on the use of water-phase change material storage in conventional solar water heating systems. Energy Conversion Management, 51, pp.1735-1740.

[38] Chaabane, M., Mhiri, H., Bournot, P.:(2014) Thermal performance of an integrated collector storage solar water heater (ICSSWH) with phase change materials (PCM). Energy Conversion Management, 78, pp.897-903.

[39] Eames, P.C., Griffiths, P.W. (2006) Thermal behaviour of integrated solar collector/storage unit with $650 \mathrm{C}$ phase change material. Energy Conversion Management, 47, pp.3611-3618.

[40] Kumar, R., Rosen,M.A. (2011a) Comparative performance investigation of integrated collector storage solar water heaters with various heat loss reduction strategies. Int. J. Energy Res., 35, pp.1179-1187.

[41] Kalogirou, S.A. (1997) Design, construction, performance evaluation and economic analysis of an integrated collector storage system. Renewable Energy, 12, pp.179-192.

[42] Kalogirou, S.A. (1999) Performance enhancement of an integrated collector storage hot water system. Renewable Energy, 16 (1-4) pp.652-655.

[43] Souliotis, M., Quinlan, P., Smyth, M., Tripanagnostopoulos, Y., Zacharopoulos, A., Ramirez, M., Yianoulis, P. (2011) Heat retaining integrated collector storage solar water heater with asymmetric CPC reflector. Solar Energy, 85 (10) pp.2474-2487.

[44] Borello, D., Corsini, A., Delibra, G., Evangelisti, S., Micangeli, A.(2012) Experimental and computational investigation of a new solar integrated collector storage system. Applied Energy, 97, pp.982-989.

[45] Garg, H.P. (1975) Year round performance studies on a built-in storage type solar water heater at Jodhpur, India. Solar Energy, 17 (3), pp.167-172. 
[46] Saleh, H.K. (2012) Thermal Performance of a domestic solar water heater. J. Sci., 23 (1), pp.137-143

[47] Mohsen, M.S., Akash, B.A.(2002) On integrated solar water heating system. Int. Commun. Heat Mass Transf., 29, pp.135-140

[48] Mohsen, M.S., Al-Ghandoor, A., Al-Hinti, I.(2009) Thermal analysis of compact solar water heater under local climatic conditions. Int. Commun. Heat Mass Transf., 36, pp.962-968.

[49] Currie, J., Garnier, C., Muneer, T., Grassie, T., Henderson, D. (2008) Modelling bulk water temperature in integrated collector storage systems. Building Services Engineering Research and Technology, 29 (3), pp.203-218

[50] Garnier, C., Currie, J., Muneer, T. (2009) Integrated collector storage solar water heater: temperature stratification. Applied Energy, 86, pp.1465-1469.

[51] Garnier, C., Muneer, T., Currie, J. (2011) Thermal model for performance prediction of integrated collector storage systems. J. Renewable Sustainable Energy, 3, 013104

[52] Henderson, D., Junaidi, H., Muneer, T., Grassie, T. and Currie, J. (2007) Experimental and CFD investigation of an ICSSWH at various inclinations, Renewable and Sustainable Energy Reviews, 11, pp. 1087-1116.

[53] Ecevit, A., Al-Shaiah, A.M., Apodin, E.D.(1989) Triangular built-in-storage solar water heater. Solar Energy, 42 (3), pp.253-265.

[54] Kaushik, S.C., Kumar, R., Garg, H.P., Prakash, J. (1994) Transient analysis of a triangular built-in storage solar water heater under winter conditions. Heat Recovery Systems and CHP., 14(4), pp.337-341

[55] Soponronnarit, S., Taechapiroj, C., Tia, S.(1994) Comparative studies of built-instorage solarwater heaters. RERIC Int. Energy J., 16(1), pp.11-26

[56] Cruz, J.M.S., Hammond, G.P., Reis, A.J.P.S. (2002) Thermal performance of a trapezoidal-shaped solar collector/energy store. Applied Energy, 73, pp.195-212

[57] Fraisse, G., Pailha, M., Swiatek, M., Paulus, C., Souza, J., Cosnier, M., Tixier, N. (2014) Study of a New Integrated Solar Collector. Energy Procedia, 57, pp.2506-2514.

[58] Sridhar, A. and Reddy, K.S. (2007) Transient analysis of modified cuboid solar integrated collector- storage system. Applied Thermal Engineering, 27, pp.330346

[59] Kumar, R., Rosen, M.A. (2011b) Integrated collector-storage solar water heater with extended storage unit. Appl. Therm. Eng. 31, pp.348-354

[60] Smyth, M., McGarrigle, P., Eames, P.C., Norton, B. (2005) Experimental comparison of alternative convection suppression arrangements for concentrating integral collector storage solar water heaters. Solar Energy, 78, pp.223-233.

[61] Smyth, M., Eames, P.C., Norton, B. (2003) Heat retaining integrated collector/storage solar water heaters. Solar Energy, 75, pp.27-34.

[62] Garnier, C. (2011) Solar thermal collector module for houses and flats. In Proceedings of the $8^{\text {th }}$ International Conference SOLARIS 2011. Brno, Czech Republic. 
[63] Junaidi HA, Henderson D, Muneer T, Grassie T, Currie J. (2006) Study of stratification in a (ICSSWH) integrated collector storage solar water heater: In: Proceedings of the 9th AIAA/ASME joint conference, San Francisco.

[64] Furbo, S. and Mikkelsen S.E. (1987) Low flow operation an advantage for solar heating systems? W.H. Bloss, F. Pfisterer (Eds.), Advances in Solar Energy technology, Pergamon Pres, Oxford, Vol. 1, pp.962-966.

[65] Hollands, K.G.T. and Lightstone M.F. (1989) A review of low flow, stratified-tank solar water heating systems. Solar Energy, 43 (2) pp.97-105

[66] Duffie, J. and Beckman, W. (1974) Solar Energy Thermal Processes, New York: John Wiley \& Sons, Inc

[67] Muneer T. (1985) Effect of design parameter on performance of built-in storage solar water heater. Energy Conservation and Management, 3 (25) pp. 277-281.

[68] Ghaddar, N.K. (1994) Stratified storage tank influence on performance of solar water heating system tested in Beirut. Renewable Energy, 4 (8) pp.911-925.

[69] Van Koppen C.W.J., Thomas J.P.X., Veltkamp W.B. (1979) The actual benefits of thermally stratified storage in a small and medium size solar system. In: Proceedings of ISES Solar World Congress, Atlanta, USA; pp.579-580.

[70] Chung,J.D., Cho, S. H., Tae, C.S., Yoo, H. (2008) The effect of diffuser configuration on thermal stratification in a rectangular storage tank. Renewable Energy, 33 (10) pp.2236-2245.

[71] Madhlopa, A., Mgawi, R., Taulo, J. (2006) Experimental study of temperature stratification in an integrated collector-storage solar water heater with two horizontal tanks. Solar Energy, 80 (8) pp.989-1002.

[72] Eames, P.C. and Norton, B. (1998) The effect of tank geometry on thermally stratified sensible heat storage subject to low Reynolds number flows. International Journal of Heat and Mass Transfer, 41 (14) pp.2131-2142.

[73] Altuntop, N., Arslan,M., Ozceyhan,V., Kanoglu, M.(2005) Effect of obstacles on thermal stratification in hot water storage tanks. Applied Thermal Engineering, 25 (14-15) pp. 2285-2298.

[74] Lavan,Z. and Thompson, J. (1977) Experimental study of thermally stratified hot waterstorage tanks. Solar Energy, 19 (5) pp.519-524.

[75] Hahne, E. and Chen, Y. (1998) Numerical study of flow and heat transfer characteristics inhot water stores. Solar Energy, 64 (98) pp.9-18.

[76] Nelson, J., Balakrishnan, A. Srinivasa Murthy, S. (1999) Experiments on stratified chilled water tanks. J. Refrig. 22, pp.16-234.

[77] Hegazy,A. A. (2007) Effect of inlet design on the performance of storage-type domestic electrical water heaters. Applied Energy, 84 (12) pp. 1338-1355.

[78] Zurigat, Y.H., Ghajar, A.J. and Moretti, P.M. (1988) Stratified thermal storage tank inlet mixing characterization. Applied Energy, 30, pp. 99-111

[79] Van Berkel, J. (1996) Mixing in thermally stratified energy stores. Solar Energy, 58 (4-6) pp.203-211.

[80] Wildin, M.W. (1990) Diffuser design for naturally stratified thermal storage. ASHRAE Transactions, 96 (1) pp. 1094-1102 
[81] Hegazy, A.A. and Diab, M.R.(2002) Performance of an improved design for storage-type domestic electric water heaters. Applied Energy, 71 (4) pp. 287306

[82] Grassie, T., Junaidi, H., Muneer, T., Currie, J. and Henderson, D. (2006) Study of the modified built-in-storage (integrated collector storage) solar water heater for Scottish weather conditions. In: Proceedings of Eurosun 2006, Glasgow, UK.

[83] Muneer, T., Younes, S., Lambert, N. and Kubie, J. (2006) Life cycle assessment of a medium-sized photovoltaic facility at a high latitude location, Part A: Journal of Power Energy: Proceedings of the Institution of Mechanical Engineers, 220 (6) pp. 517-524.

[84] Ingram, D.M., Causon, D.M. and Mingham, C.G. (2003) Developments in Cartesian cut cell methods. Mathematics and Computers in Simulation, 61 (3-6) pp. 561-572.

[85] Garnier, C., Currie, J. I., Muneer, T. and Girard, A. (2008) Computational study of an integrated collector storage solar water heater. In: Proceedings of EUROSUN 2008. Lisbon, Portugal.

[86] Gertzos, K.P., Pnevmatikakis, S.E. and Caouris, Y.G. (2008) Experimental and numerical study of heat transfer phenomena, inside a flat-plate integrated collector storage solar water heater (ICSSWH), with indirect heat withdrawal. Energy Conversion and Management, 49 (11) pp. 3104-3115.

[87] Ansys Inc. (2009) Training Manual. Sheffield : s.n.

[88] McLennan, C. (2006) Solar Water Heating. Edinburgh : School of Engineering, Napier University.

[89] General Register Office for Scotland (2012) Household Projections for Scotland. [Online] 14 June 2012. [Cited: 6 July 2012.] < http://www.groscotland.gov.uk/files2/stats/household-projections/2010-based/2010-basedhousehold-proj-publication.pdf. >

[90] Goforth, M. A., Gilchrist, G. W. and Sirianni, J. D. (2002) Cloud effects on thermal downwelling sky radiance. In: Proceeding of SPIE. Thermosense XXIV. Orlando. Vol. 4710.

[91] Oshchepkova M. Yu. and Frid S. E. (2015a) Thermal Stratification in Storage Tanks of Integrated Collector Storage Solar Water Heaters. Applied Solar Energy, 51 (1) pp. 74-82.

[92] Oshchepkova M. Yu. and Frid S. E. (2015b) Stratification in a Solar Tank Accumulator during Rapid Displacement of Hot Water. Applied Solar Energy, 51 (3) pp. 177-182.

[93] Oshchepkova M. Yu. and Frid S. E. (2016) Modelling of the Warm Water Displacement from Stratified Tanks of Integrated Collector Storage Solar Water Heaters. Applied Solar Energy, 52 (3) pp. 173-177.

[94] Devanarayanan, K. and Kalidasa Murugavel, K. (2014) 'Integrated collector storage solar water heater with compound parabolic concentrator - Development and progress', Renewable and Sustainable Energy Reviews. Elsevier, 39, pp. 51-64. doi: 10.1016/j.rser.2014.07.076 
[95] Ziapour, B. M., Palideh, V. and Mokhtari, F. (2016) 'Performance improvement of the finned passive PVT system using reflectors like removable insulation covers', Applied Thermal Engineering. Elsevier Ltd, 94, pp. 341-349. doi: 10.1016/j.applthermaleng.2015.10.143

[96] Benrejeb, R., Helal, O., Chaouachi, B., (2015) Optical and thermal performances improvement of an ICS solar water heater system Solar Energy, 112, pp. 108119

[97] Arnaoutakis, N., Souliotis, M., Papaefthimiou, S., (2017) Comparative experimental Life Cycle Assessment of two commercial solar thermal devices for domestic applications, Renewable Energy 111, pp. 187-200

[98] Varghese, J., Samsher and Manjunath, K. (2017) 'A parametric study of a concentrating integral storage solar water heater for domestic uses', Applied Thermal Engineering. Elsevier Ltd, 111, pp. 734-744. doi: 10.1016/j.applthermaleng.2016.09.127

[99] Hamed, M., Fallah, A. and Ben Brahim, A. (2017) 'Numerical analysis of an integrated storage solar heater', International Journal of Hydrogen Energy. Elsevier Ltd, 42(13), pp. 8721-8732. doi: 10.1016/j.ijhydene.2016.07.116 [100] Hamed, M., Fallah, A. and Ben Brahim, A. (2017) Numerical analysis of charging and discharging performance of an integrated collector storage solar water heater, International Journal of Hydrogen Energy. Elsevier Ltd, 42(13), pp. 8777-8789. doi: 10.1016/j.jhydene.2016.11.179 
Appendix A: Thermophysical property data

Table A1: Water properties as functions of temperature

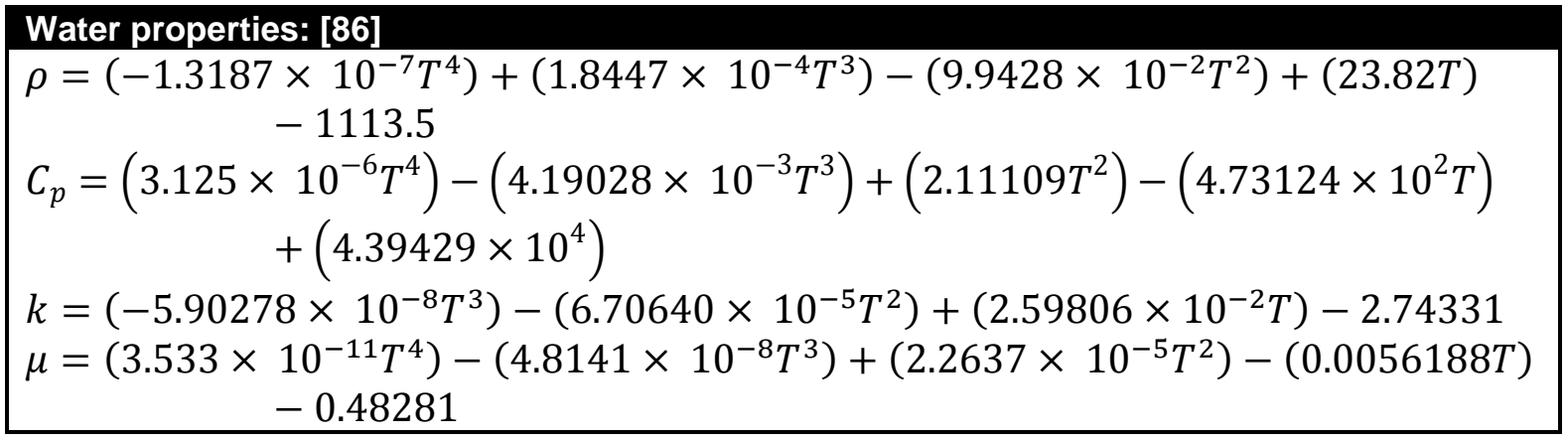

Table A2: Air properties as functions of temperature

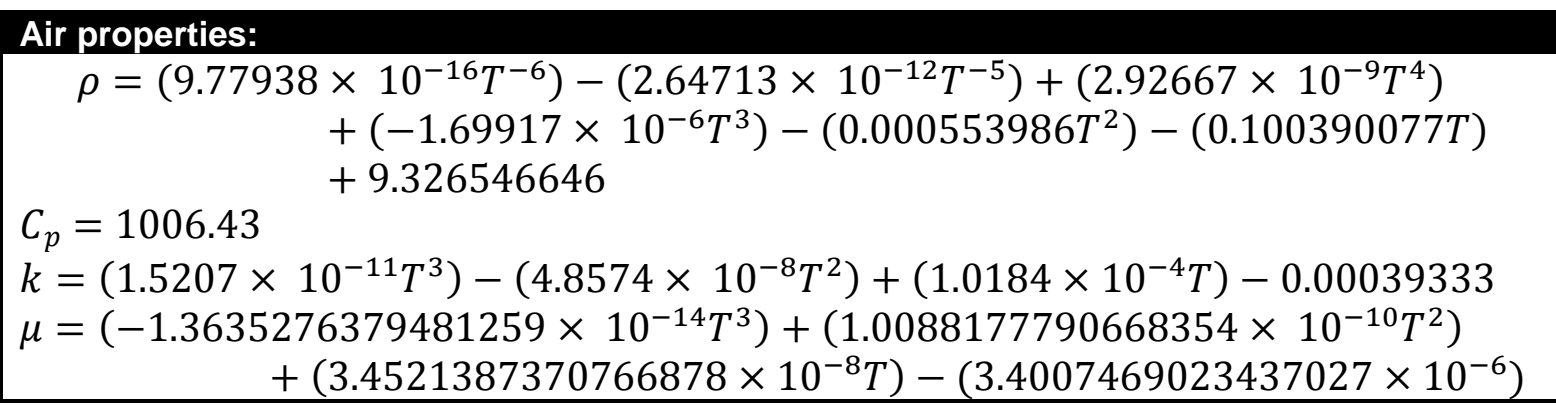

Table A3: ICS-SWH material properties

\begin{tabular}{|c|c|c|c|}
\hline Material & $\rho\left(\mathrm{kg} / \mathrm{m}^{3}\right)$ & $C_{p}(\mathrm{~kJ} / \mathrm{kg} \cdot \mathrm{K})$ & $k(\mathrm{~W} / \mathrm{m} . \mathrm{K})$ \\
\hline Aluminum & 2719 & 871 & 202.4 \\
\hline Aerogel & 120 & 1250 & 0.012 \\
\hline Glazing & 2800 & 840 & 5.8 \\
\hline Copper & 8978 & 381 & 387.6 \\
\hline
\end{tabular}

